\title{
High-Temporal Resolution Observations of the 27 May 2015 Canadian, Texas, Tornado Using the Atmospheric Imaging Radar
}

\author{
CASEY B. GRIFFIN \\ School of Meteorology, and Advanced Radar Research Center, University of Oklahoma, Norman, Oklahoma \\ DAVID J. BODINE AND JAMES M. KuRDZO \\ Advanced Radar Research Center, University of Oklahoma, Norman, Oklahoma \\ ANDREW MAHRE AND RoBert D. PALMER \\ School of Meteorology, and Advanced Radar Research Center, University of Oklahoma, Norman, Oklahoma
}

(Manuscript received 21 August 2018, in final form 16 January 2019)

\begin{abstract}
On 27 May 2015, the Atmospheric Imaging Radar (AIR) collected high-temporal resolution radar observations of an EF-2 tornado near Canadian, Texas. The AIR is a mobile, X-band, imaging radar that uses digital beamforming to collect simultaneous RHI scans while steering mechanically in azimuth to obtain rapid-update weather data. During this deployment, $20^{\circ}$-by- $80^{\circ}$ (elevation $\times$ azimuth) sector volumes were collected every $5.5 \mathrm{~s}$ at ranges as close as $6 \mathrm{~km}$. The AIR captured the late-mature and decaying stages of the tornado. Early in the deployment, the tornado had a radius of maximum winds (RMW) of $500 \mathrm{~m}$ and exhibited maximum Doppler velocities near $65 \mathrm{~m} \mathrm{~s}^{-1}$. This study documents the rapid changes associated with the dissipation stages of the tornado. A 10-s resolution time-height investigation of vortex tilt and differential velocity $\Delta V$ is presented and illustrates an instance of upward vortex intensification as well as downward tornado decay. Changes in tornado intensity over periods of less than $30 \mathrm{~s}$ coincided with rapid changes in tornado diameter. At least two small-scale vortices were observed being shed from the tornado during a brief weakening period. A persistent layer of vortex tilt was observed near the level of free convection, which separated two layers with contrasting modes of tornado decay. Finally, the vertical cross correlation of vortex intensity reveals that apart from the brief instances of upward vortex intensification and downward decay, tornado intensity was highly correlated throughout the observation period.
\end{abstract}

\section{Introduction}

High-temporal resolution radar observations are crucial for the study of tornadoes because of the rapidly changing nature of tornadoes. Tornadoes can intensify and weaken over short time scales, and many weak tornadoes have entire life cycles that are much shorter than the volumetric update time of traditional, mechanically steered radars. Volumetric update times much less than $1 \mathrm{~min}$ are required to properly sample the evolution of tornadoes, with temporal resolution of $10 \mathrm{~s}$ or less necessary to capture some of the more rapidly evolving features (Bluestein et al. 2010). Mobile radars currently capable of volumetric updates of $\sim 30 \mathrm{~s}$ or less include the rapid-scan Doppler on Wheels (Wurman

\footnotetext{
Corresponding author: Casey B. Griffin, casey.griffin@ou.edu
}

and Randall 2001), the Mobile Weather Radar 2005 X-band Phased Array (MWR-05XP; Bluestein et al. 2010), the rapid X-band polarimetric radar (RaXPol; Pazmany et al. 2013), and the Atmospheric Imaging Radar (AIR; Isom et al. 2013; Kurdzo et al. 2017). In addition to high-temporal resolution, these radars have the advantage of close-range deployments (Wurman et al. 1996), which allow for much better spatial and low-level sampling of tornadoes and mesocyclones compared to stationary radars (e.g., Wurman and Gill 2000; Bluestein and Pazmany 2000; Bluestein et al. 2007a; Kosiba and Wurman 2013; Wurman and Kosiba 2013; Weiss et al. 2014). The finescale spatial resolution provided by mobile radars maximizes the benefits of high-temporal updates for tornado applications by allowing radars to observe rapidly evolving small-scale phenomena. 
Recent tornado studies using rapid-update radars have illustrated the importance of short-lived tornadic subvortices on a tornado's intensity and damage potential (Snyder and Bluestein 2014; Wakimoto et al. 2016). Rapid-scan radars are also uniquely qualified to interrogate the vertical evolution of rotation during tornadogenesis (Houser et al. 2015; French et al. 2013) and tornado decay (French et al. 2014). Houser et al. (2015) found that subtornadic rotation in the 24 May 2011 El Reno, Oklahoma, EF-5 tornado first developed below $1 \mathrm{~km}$ and then intensification of rotation to tornadic intensity occurred simultaneously throughout the column when rotation increased aloft (e.g., above $3 \mathrm{~km}$ ). During decay, French et al. (2014) found that the 5 June 2009 Goshen County, Wyoming, tornado first dissipated near a height of $1.5 \mathrm{~km}$ and then proceeded to decay in an "inside out" manner at progressively higher and lower elevations. The level where dissipation first occurred was found to be just above where the tornado motion was most influenced by strong rear-flank gust front outflow. Houser et al. (2015) also noted a similar decay mechanism in the El Reno tornado with tornado dissipation first occurring in a stable layer between 1.5 and $3 \mathrm{~km}$ above the ground.

Rapid-update radars have observed that tornado intensity can be highly variable, sometimes periodic, over short time scales (e.g., Wurman and Kosiba 2013) and that tornado intensity in the low levels (e.g., below $1 \mathrm{~km}$ ) may be uncorrelated from tornado intensity aloft (French et al. 2014; Mahre et al. 2018). Additional topics of recent investigation using high-temporal resolution radar data include the impact that rapidly evolving storm-scale processes, such as rear-flank gust front surges, have on the tornado life cycle (Houser et al. 2015) and the rapid evolution of the distribution of tornadic debris (Kurdzo et al. 2015; Houser et al. 2016; Mahre et al. 2018). However, the number of hightemporal resolution tornado cases is still extremely limited, and thus it remains unclear whether or not these past findings can be generalized. A range of tornado cases of varying tornado size and intensity are needed to better understand the diversity of tornado behavior and document whether similarities exist in tornadogenesis and tornado dissipation modes.

Toward the goal of a broader view of rapid tornado evolution, the present study interrogates close-range tornado observations collected by the AIR. The AIR is a mobile, X-band phased-array radar that collects hightemporal resolution, vertically continuous volumetric observations of tornadoes. On 27 May 2015, the AIR collected 5.5-s temporal resolution observations of an EF-2 rated tornado near Canadian, Texas, with maximum Doppler velocities of $65 \mathrm{~m} \mathrm{~s}^{-1}$ during the scanning period and at its widest, had a radius of maximum winds (RMW) of $500 \mathrm{~m}$. The nearly simultaneous volumetric data collection within the Canadian tornado provides a unique opportunity to interrogate the vertical structure of a tornado during decay without having to account for translation or evolution of the vortex between elevation scans.

This study documents the vertical evolution of tornado intensity during tornado decay with the goal of identifying if specific layers within the tornado are important for triggering tornado dissipation. Studies by French et al. (2014) and Houser et al. (2015) have previously documented tornado decay with high-temporal resolution and have provided early insight into the vertical behavior of tornadoes during dissipation. However, the data in this case have better spatial resolution compared to French et al. (2014) and better lowlevel coverage than Houser et al. (2015). Understanding where tornadoes first weaken and how decay evolves in time and space could inform future investigations into the vorticity budget of the tornado using models, multiple-Doppler analyses, or a combination of both (e.g., Marquis et al. 2012, 2016). In addition to contributing to a better understanding of why tornadoes dissipate, rapid observations that determine how late-life cycle tornadoes behave have the potential to inform forecasters when to let warnings expire if phased-array radars are implemented operationally in the future.

In addition to investigating tornado decay, this study also documents two instances of small-scale vortices being shed from the parent tornado, which occur during a brief tornado weakening period and may have contributed to the transport of angular momentum away from the tornado. A detailed evolution of tornado tilt through multiple layers of the tornado is presented. French et al. (2014) previously found no relationship between tornado tilt and vortex intensity; however, this study calculates tornado tilt with much finer vertical resolution in order to investigate much smaller layers within the tornado rather than just the overall tornado inclination. Finally, tornado intensity is compared to vortex diameter to interrogate the role of conservation of angular momentum on tornado intensity and the vertical cross correlation of tornado intensity is analyzed.

\section{Methods}

\section{a. Atmospheric imaging radar and case overview}

The AIR is a mobile, rapid-scan, X-band, phased-array imaging radar designed and constructed by the Advanced Radar Research Center (Isom et al. 2013). The AIR transmits a $20^{\circ}$ in elevation by $1^{\circ}$ in azimuth horizontally 
polarized fan beam and receives data using a 36-element array with a vertically oriented baseline. The 36 channels of received data are combined using digital beamforming (Mead et al. 1998) to reconstruct 20 (total) $1^{\circ} \times 1^{\circ}$ beams resulting in a simultaneous RHI with each pulse, which is mechanically steered in azimuth to collect volumetric data. In the present study, Fourier (nonadaptive) digital beamforming is used.

The 27 May 2015 Canadian, Texas, EF-2 tornado had a life span of approximately $10 \mathrm{~min}$, forming around 2157 UTC and visually dissipating at 2207 UTC. Beginning at 2203 UTC, the AIR collected approximately $4.5 \mathrm{~min}$ of data in $20^{\circ}$ by $80^{\circ}$ volumetric sectors with 5.5 -s temporal resolution. The range to the tornado was between 5 and $6 \mathrm{~km}$ for the deployment with the closest distance occurring at the beginning of the sampling period. Corresponding beam heights range from 50 to $2000 \mathrm{~m}$ above radar level (ARL) for the center of the beams between $0^{\circ}$ and $20^{\circ}$ elevation. The presented data are oversampled to $0.5^{\circ}$ in both azimuth and elevation and have a $37.5-\mathrm{m}$ gate spacing in range that is oversampled to $30 \mathrm{~m}$ (Kurdzo et al. 2014). For this case, the Nyquist velocity was $25 \mathrm{~m} \mathrm{~s}^{-1}$ and the radar truck was level during data collection. Velocity aliasing was manually corrected during post processing. High spectrum width, low reflectivity data points were subjectively removed if their Doppler velocity looked suspect for all permutations of dealiasing. Spectrum width was used to identify large gradients in Doppler velocity and aid in the identification of the zero isodop. However, in some instances ambiguities in the placement of zero isodop exist, especially regarding the distinction between folded outbound velocities and weak inbound velocities in the core of the tornado. For times with particularly high uncertainty, the position of the zero isodop was selected to best preserve temporal and vertical continuity. Nevertheless, changing the location of the zero isodop a few radials in either direction would have little or no impact on the presented results because of the displacement of the strongest Doppler velocities from the center of the tornado.

\section{b. Time-height plots}

The 5.5-s volumetric updates of the AIR can be leveraged to interrogate the vertical evolution of tornado characteristics. Time-height plots of differential velocity $\Delta V$ and tornado vortex tilt are calculated for the entire 4.5-min deployment for the Canadian, Texas, tornado. For the time-height plots, a three-time (20-s) moving average is applied. An additional three-height (100-m) moving average is applied to the vortex tilt plots to filter out noise. The data are vertically interpolated to the beam heights of the first volume scan. Because the tornado was nearly stationary during the deployment, the maximum vertical interpolation is $\sim 20 \mathrm{~m}$ and the resulting changes in the data are negligible. Values of $\Delta V$ are calculated by subjectively selecting the tornado center using radial velocity and the weak echo hole (WEH) as a first guess and searching for the maximum and minimum velocities within $1000 \mathrm{~m}$. The locations of the maximum inbound and outbound velocities were manually checked to mitigate possible errors. Vortex tilt is calculated by determining the angle between the subjectively identified vortex center at the height above and height below a given analysis level (roughly $50 \mathrm{~m}$ above and below). The analyses were run multiple times with different subjectively chosen centers of the vortex and it was determined that the analyses were not qualitatively sensitive to small changes (on the order of tens of meters) in the choice of vortex center. Additionally, the analyses were also not qualitatively sensitive to tilt being calculated over a $0.5^{\circ}, 1.0^{\circ}$, or $2^{\circ}$ angular depth.

\section{Results}

\section{a. High-temporal resolution observations}

The maximum sampled intensity of the Canadian, Texas, tornado occurred at 2203:52 UTC, in the first volume of data collected by the AIR (Figs. 1a,b). At this time, the tornado had maximum $\Delta V$ of $110 \mathrm{~m} \mathrm{~s}^{-1}$, a RMW ranging from $200 \mathrm{~m}$ at $100 \mathrm{~m}$ ARL (Fig. 2b) to $500 \mathrm{~m}$ at $500 \mathrm{~m}$ ARL (Fig. 2d), and a broad, 500-m-wide region with Doppler velocities exceeding $40 \mathrm{~m} \mathrm{~s}^{-1}$ in magnitude. Additionally, the tornado exhibited concentric WEHs similar to what has previously been observed by Wurman and Gill (2000), Wurman et al. (2007), Bluestein et al. (2007a), and Wakimoto et al. (2016). It is possible that the concentric WEHs represent different scatterer types (e.g., raindrops and small debris) similar to what was noted by Wakimoto et al. (2016). However, the AIR does not have dual-polarimetric capabilities to confirm the presence of debris. Additionally, the nearest WSR-88D is approximately $140 \mathrm{~km}$ away preventing adequate supplemental low-level polarimetric observations. RaXPol observations (Z. Wienhoff 2018, personal communication) from $\sim 2$ min later did not show a polarimetric tornadic debris signature, but the lowest RaXPol scan was above where the AIR observed the inner WEH, which is hypothesized to be debris. The tornado rapidly weakened during the first minute of data collection (Figs. 1d,f). By 2204:56 UTC, the maximum $\Delta V$ decreased to $\sim 80 \mathrm{~m} \mathrm{~s}^{-1}$ and only a $\sim 100-\mathrm{m}$ wide region of Doppler velocities exceeding $40 \mathrm{~m} \mathrm{~s}^{-1}$ in magnitude was present (Fig. 1f). The WEH rapidly filled in and became less symmetric during this weakening 

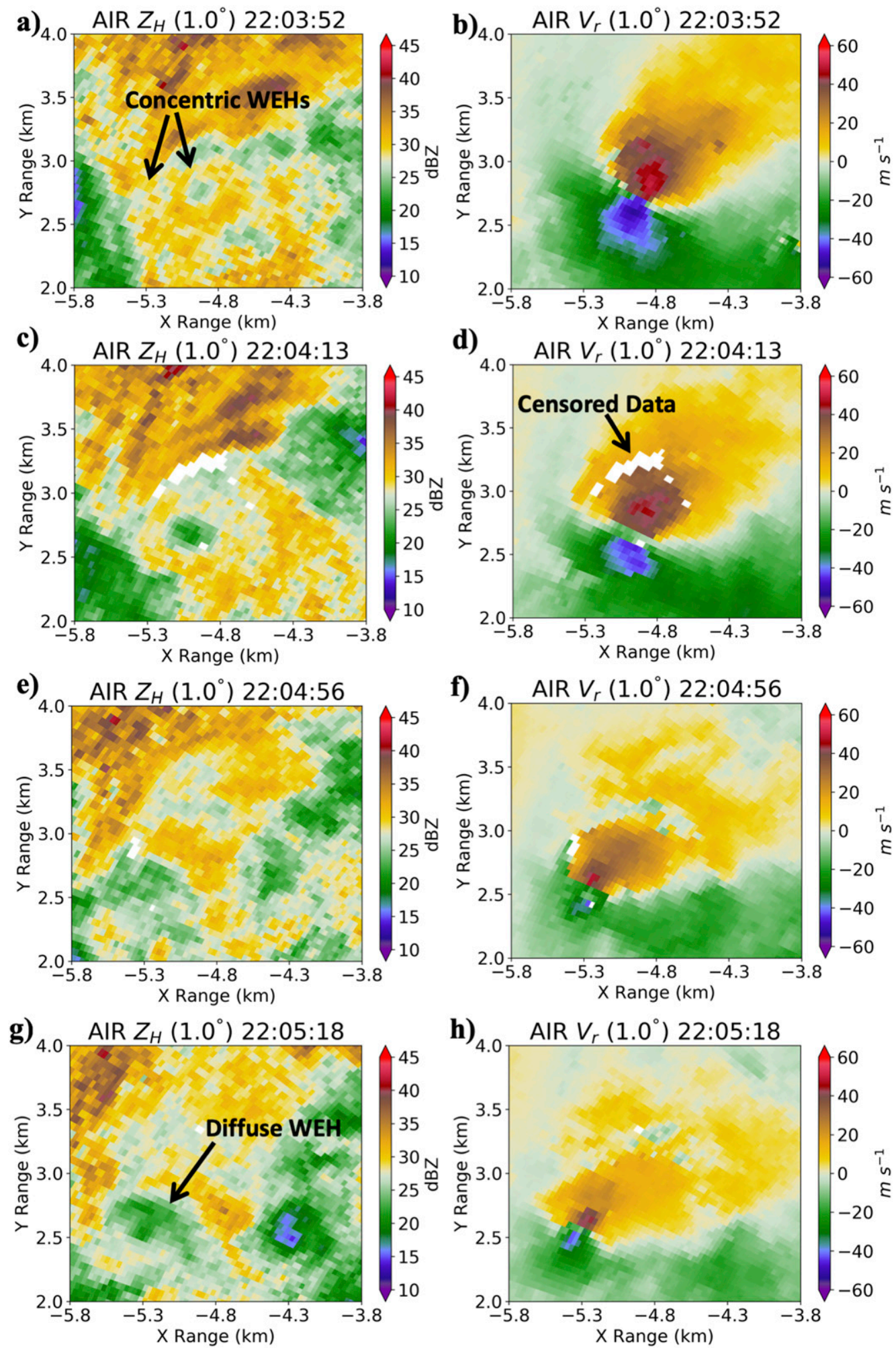

FIG. 1. PPI plots of (a),(c),(e),(g) reflectivity (dBZ) and (b),(d),(f),(h) radial velocity $\left(\mathrm{m} \mathrm{s}^{-1}\right)$ at $1^{\circ}$ elevation at (a),(b) 2203:52; (c),(d) 2204:13; (e),(f) 2204:56; and (g),(h) 2205:18 UTC. White pixels here and elsewhere represent censored data. 


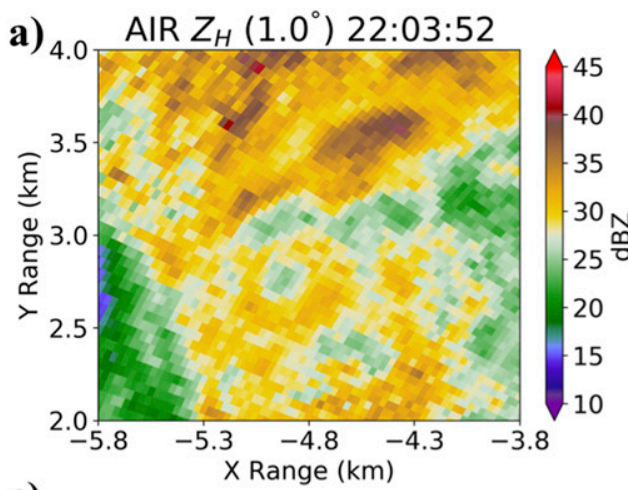

c)

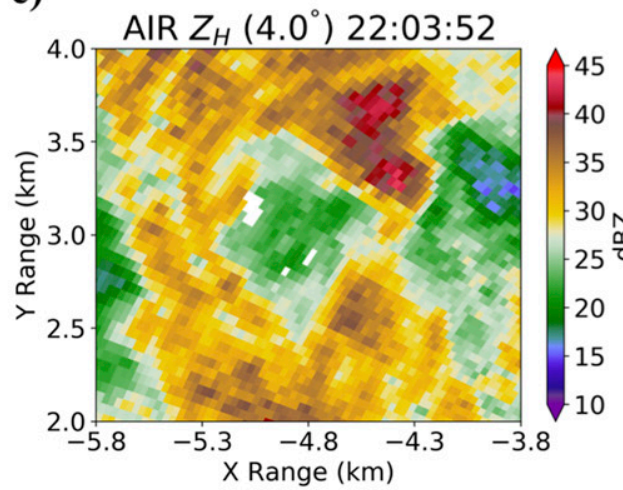

e) $\operatorname{AIR} Z_{H}\left(7.0^{\circ}\right) 22: 03: 52$

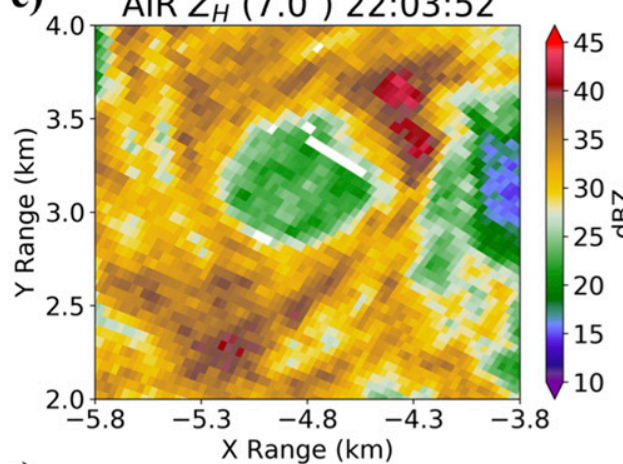

g)

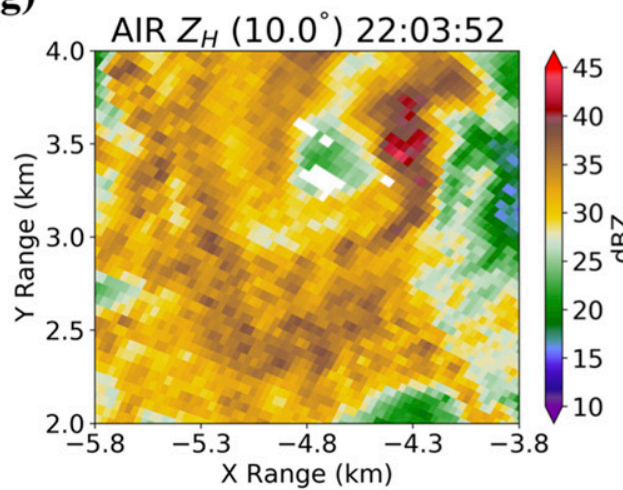

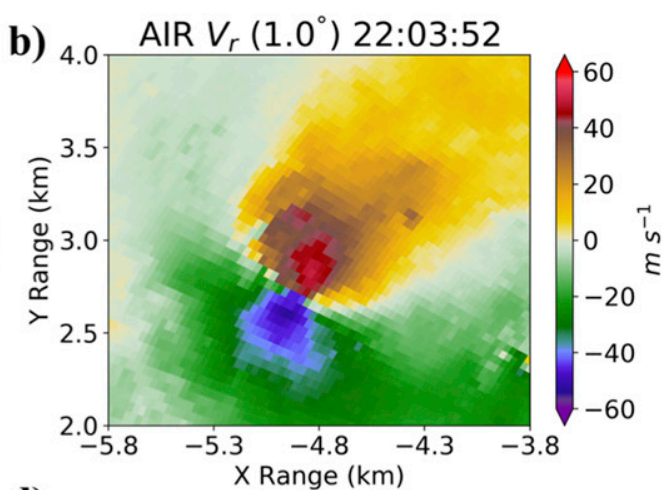

d)
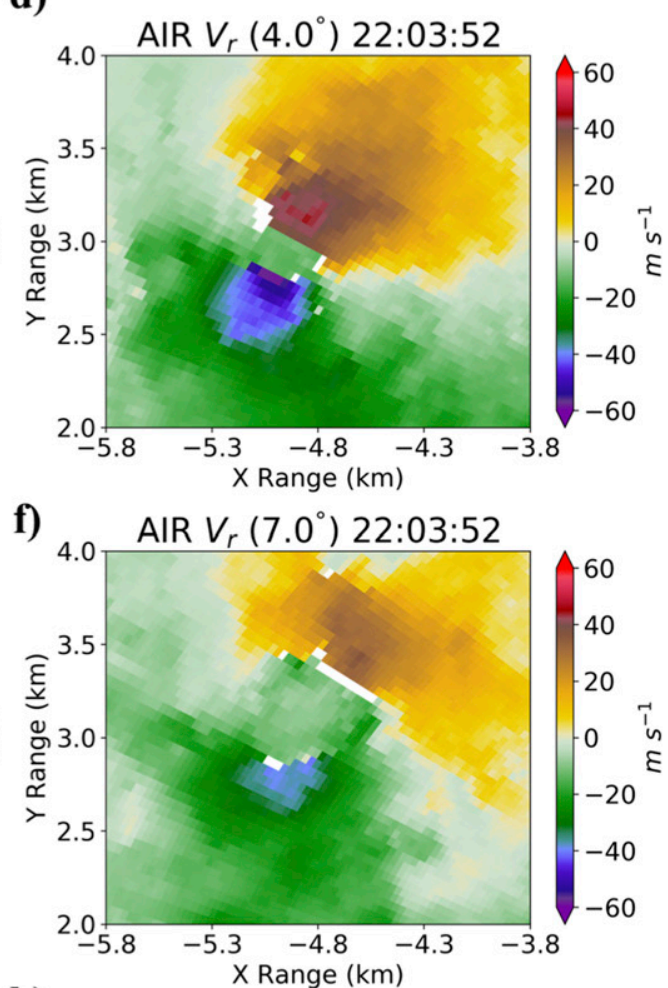

h)

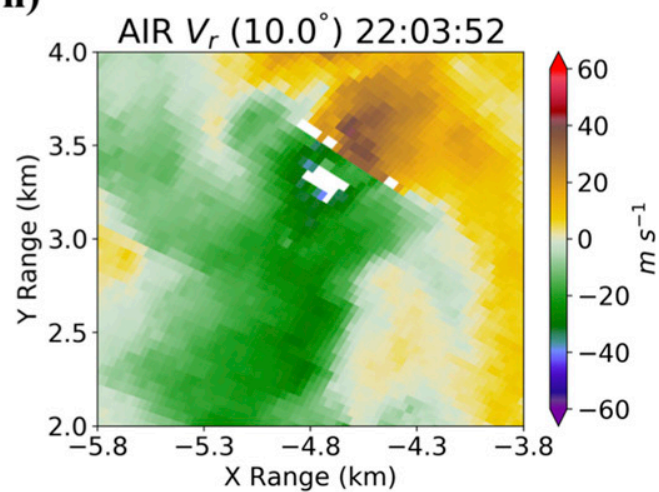

FIG. 2. PPI plots of (a),(c),(e),(g) reflectivity (dBZ) and (b),(d),(f),(h) radial velocity $\left(\mathrm{m} \mathrm{s}^{-1}\right)$ at (a),(b) $1^{\circ}$; (c),(d) $4^{\circ}$; (e),(f) $7^{\circ}$; and (g),(h) $10^{\circ}$ elevation valid at $2203: 52$ UTC. The elevations roughly correspond with $100,400,750$, and $1000 \mathrm{~m}$ ARL. 
phase (Figs. 1c,e), becoming poorly defined at low levels by 2204:56 UTC (Fig. 1e). By 2205:18 UTC, the tornado diameter and intensity (Fig. 1h) was similar to what it was at 2204:56 UTC, but a diffuse WEH became reestablished (Fig. 1g). The tornado persisted with similar intensity for approximately another minute before it completed its decay. The vertical and temporal evolution of tornado intensity will be discussed in further detail later in this section.

As noted by Kurdzo et al. (2017), an interesting feature of the Canadian tornado is the weak radial velocities in the core of the tornado (Figs. 2d,f) and large separation of the maximum inbound and maximum outbound radial velocities at early times, especially between $3^{\circ}$ and $10^{\circ}$ in elevation (400-1000 m ARL). A similar pattern of large separation between maximum inbound and outbound radial velocities with weak core Doppler velocities was observed by RaXPol in Wakimoto et al. (2016) when the 2013 El Reno tornado was exhibiting multiple vortex structure [cf. Fig. 15 in Wakimoto et al. (2016)]. However, in the Canadian case these observations were seen at a beam height of $\sim 400-600 \mathrm{~m}$ compared to observations in Wakimoto et al. (2016), which were at $0.5^{\circ}$ (below $100 \mathrm{~m}$ ). At $1^{\circ}$ elevation, the Canadian tornado instead exhibited a narrower core diameter ${ }^{1}$ of $\sim 150 \mathrm{~m}$ (Fig. $2 \mathrm{~b}$ ). It must be noted that the AIR and RaXPol are both low-power radars, which may have less sensitivity in areas of lower power, like the WEH. While the power returns in the WEH of the Canadian tornado were well above the noise floor of the AIR, to the authors' knowledge, the weak Doppler velocity structure in the core of tornadoes has not been observed by a higher-power radar; therefore, it is possible that the these observations are a radar artifact unique to low-power radars and not representative of the actual wind field.

Up to approximately $900 \mathrm{~m}$ ARL, the tornado widened to $600 \mathrm{~m}$ in diameter and weakened in intensity (Figs. 2d,f). Similar vertical structure to what is seen in the Canadian tornado can also be seen in model simulations of medium-swirl tornadoes with a narrow diameter near the surface and a larger diameter aloft [e.g., cf. Fig. 5 in Lewellen et al. (2000)]. In the Lewellen et al. (2000) simulations, this widening of the vortex is associated with a transition from single-cell to two-cell vortex flow. Axisymmetric wind retrievals of the Canadian tornado reveal a similar low-swirl corner flow with vortex breakdown characteristics aloft at this time;

\footnotetext{
${ }^{1}$ Here and elsewhere in the paper, the tornado diameter is defined as the distance between the maximum outbound and maximum inbound Doppler velocities within the tornado.
}

however, uncertainties in the retrieved vertical velocities arising from poor sampling of the low-level mass field preclude the inclusion of these analyses. Above $\sim 900 \mathrm{~m}$, the tornado narrowed again (Fig. 2h) and maintained a similar 350-m diameter through the highest observed elevations (not shown). The WEH narrowed in response to the tightening of the vortex aloft (Fig. 2g) and is similar in structure to the bulging WEC structure noted in Bluestein et al. (2007b). The bulging structure of the vortex and WEH continued for approximately $30 \mathrm{~s}$ and is further discussed in section $3 \mathrm{c}$.

A broken ring of high $\left(>10 \mathrm{~m} \mathrm{~s}^{-1}\right)$ spectrum width was also observed at early times near the radius where the largest radial velocities were located (Fig. 3a). Similar spectrum width ring structure has also been observed by Wurman (2002) and Snyder and Bluestein (2014) in multiple-vortex tornadoes. Locally enhanced spectrum width near tornadic subvortices was likely due to high wind shear and turbulence. Additionally, strong radial gradients in tangential velocity are one requirement for subvortices to form (e.g., Rotunno 1978; Gall 1983; Lewellen et al. 2000), which would result in high spectrum width rings in an axisymmetric framework. Video of the Canadian tornado is available at https://drive.google.com/drive/folders/ 1sG9PEEBk9obq7cGv6vqlqffyj5yb4d1S?usp=sharing) and enhanced shear regions along the zero isodop in Fig. $2 b$ also indicate that multiple vortices were present near this time.

The AIR captured at least two instances of cyclonic vortices being shed by the main circulation in rapid succession over a period of one minute (Fig. 4). The vortices first appeared on the eastern side of the tornado near the RMW and translated eastward, well beyond the RMW of the tornado where tornado subvortices are normally located (e.g., Wurman 2002). After being shed, the vortices went through a brief intensification period and reached maximum $\Delta V$ of 34 and $36 \mathrm{~m} \mathrm{~s}^{-1}$, respectively. The maxima in intensity were reached at radii of approximately 500 and $1000 \mathrm{~m}$ from the primary tornado, respectively. Maximum intensity for both vortices occurred at 2204:56 UTC (Fig. 4f), approximately $30 \mathrm{~s}$ after they exited the parent cyclone. The shed vortices were largely confined to above $400-500 \mathrm{~m}$ ARL and only briefly appeared at lower elevation angles (not shown) at 2204:56 and 2205:07 UTC when the vortices were at maximum intensity. It is possible that the vertical elongation of the vortices combined with their brief intensification signifies that vortex stretching was occurring. The vortices translated slightly eastward while the main circulation moved to the west. There did not appear to be any clear evidence of a boundary that the shed vortices were traversing, nor was there any evidence of the vortices entering the tornado prior to being shed. 

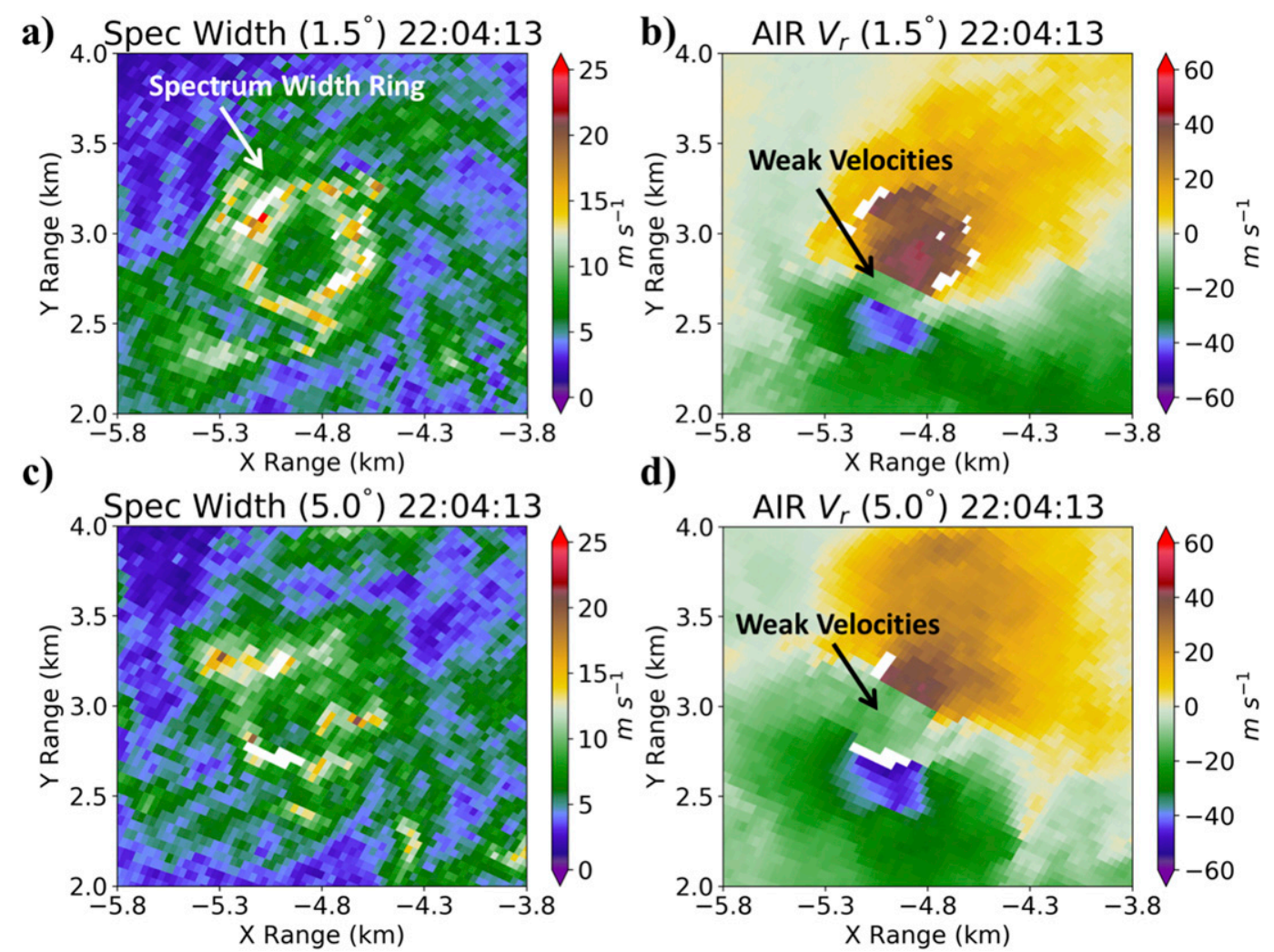

d)

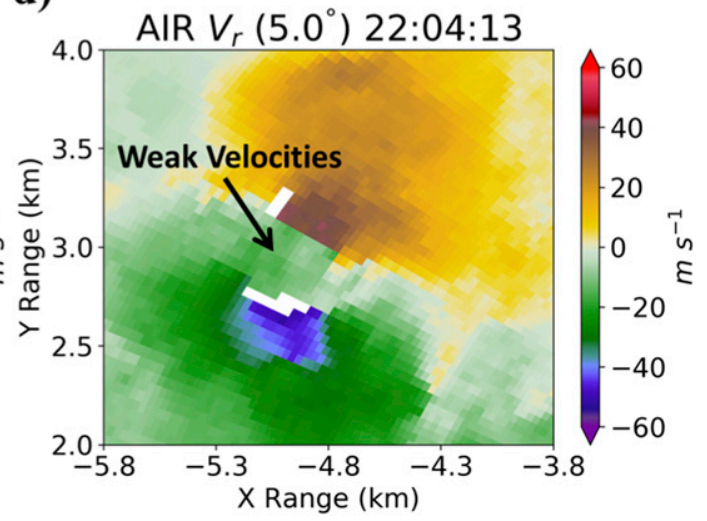

FIG. 3. PPI plots of (a),(c) spectrum width $\left(\mathrm{m} \mathrm{s}^{-1}\right)$ and (b),(d) radial velocity $\left(\mathrm{m} \mathrm{s}^{-1}\right)$, at (a),(b) $1.5^{\circ}$ and (c),(d) $5^{\circ}$ elevation valid at 2204:13 UTC.

As a result, the shed vortices may have acted to transport angular momentum away from the main circulation, which may have contributed to the weakening of the tornado.

The maximum $\Delta V$ during the deployment was $\sim 110 \mathrm{~m} \mathrm{~s}^{-1}$ and occurred during the first two analysis times (Fig. 5). The strongest $\Delta V$ occurred in the lowest $700 \mathrm{~m}$ ARL. By 2204:13 UTC, $\Delta V$ decreased to $\sim 70 \mathrm{~m} \mathrm{~s}^{-1}$ in the low levels. The tornado briefly intensified at 2204:56 UTC, following a $\sim 1$-min, relatively weak period. The restrengthening occurred first in the two lowest analysis levels and then simultaneously up to $500 \mathrm{~m}$. Brief weakening followed by restrengthening of the low-level vortex could also be seen in visual observations of the tornado at this time (0:45-1:15; see Canadian tornado video URL cited above). This bottom-up strengthening is similar to what was observed in Mahre et al. (2018) in the mature stage and similar to the vertical evolution of tornadogenesis noted in French et al. (2013), except observed during the dissipation stage of the tornado in this case.

Following the brief restrengthening of the tornado at low levels, the Canadian tornado began a final weakening phase that culminated in tornado dissipation (Fig. 5). At all observed levels above $1.25 \mathrm{~km}$ ARL, $\Delta V$ decreased nearly simultaneously to $\sim 40 \mathrm{~m} \mathrm{~s}^{-1}$ at 2205:28 UTC. Over the next $2 \mathrm{~min}$, the tornado decayed to a similar intensity in a downward direction in the layer between 400 and $1250 \mathrm{~m}$ ARL. Simultaneous weakening of the tornado occurred at 2206:33 UTC between 150 and $400 \mathrm{~m}$, approximately $1 \mathrm{~min}$ before similar tornado intensity was reached in the layer between 400 and $1000 \mathrm{~m}$ ARL. In the lowest $150 \mathrm{~m}$, weakening of the tornado slightly preceded the simultaneous weakening over the $150-400 \mathrm{~m}$ layer by approximately $20 \mathrm{~s}$. The downward decay region is similar to the inside out tornado decay noted by French et al. (2014) and Houser et al. (2015) except we do not have the observations above $2.5 \mathrm{~km}$ to compare the upper levels. Additionally, the decay in the Canadian case occurred in approximately 1-2 min, whereas in the 5 June 2009 Goshen tornado, decay took $\sim 3 \mathrm{~min}$ (French et al. 2014). The dense low-level observations provide insight into a nondescending tornado decay mode in the lowest $400 \mathrm{~m}$. The AIR sampled tornado decay with much better spatial resolution than what was sampled by the MWR-05XP during the Goshen tornado $\left[1^{\circ}\right.$ beamwidth vs $1.8^{\circ}$ beamwidth for similar ranges to the tornado and $30-\mathrm{m}$ vs 150-m range resolution; French et al. (2014)]. Also, the AIR sampled the lowest $1 \mathrm{~km}$ ARL of the Canadian 

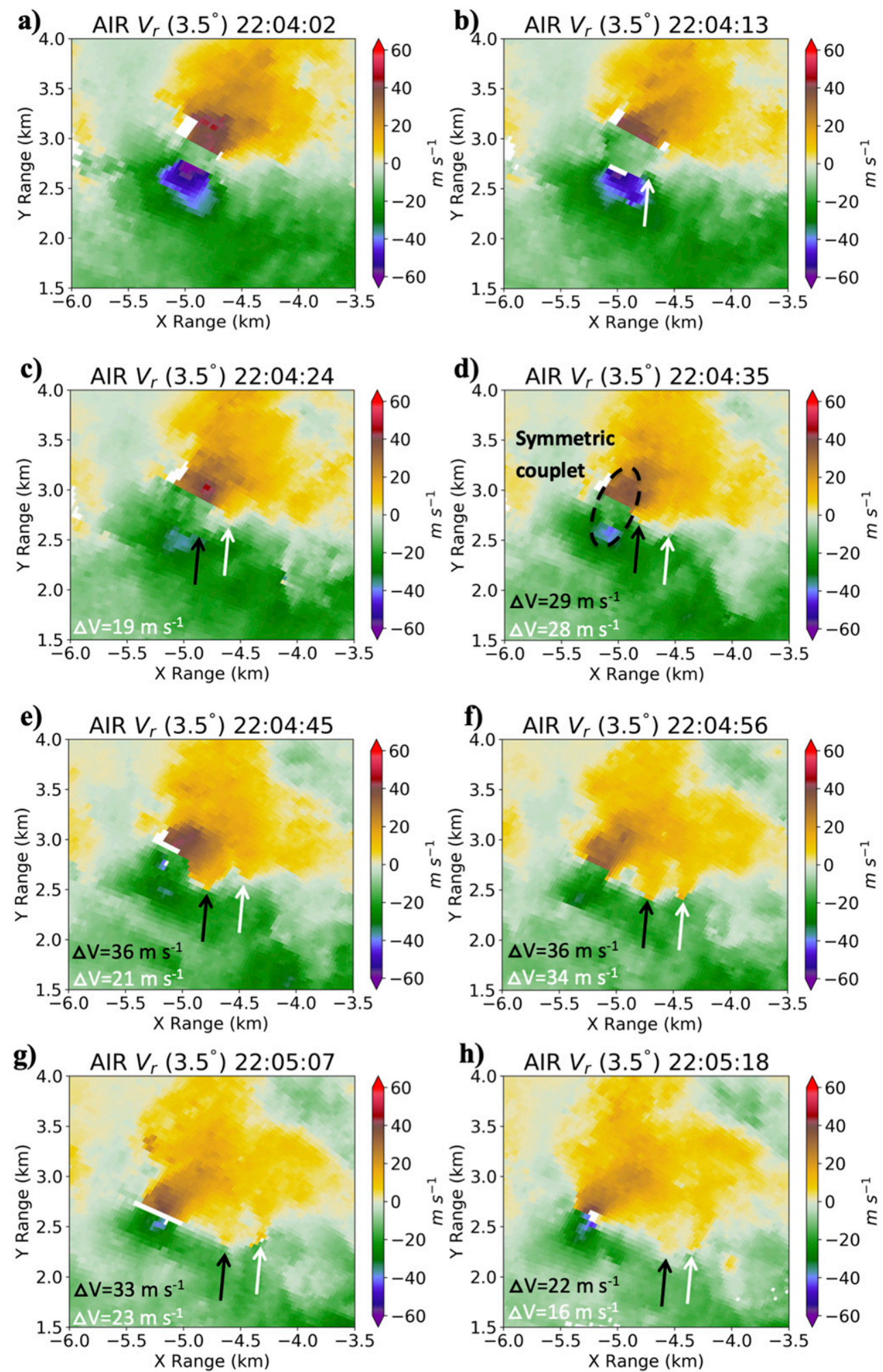

FIG. 4. PPI plots of radial velocity $\left(\mathrm{m} \mathrm{s}^{-1}\right)$ at (a) 2204:02, (b) 2204:13, (c) 2204:24, (d) 2204:35, (e) 2204:45, (f) 2204:56, (g) 2205:07, and (h) 2205:18 UTC at 3.5 elevation. Arrows indicate the location of the shed vortices. Maximum $\Delta V$ of each vortex is shown after it has been shed. 


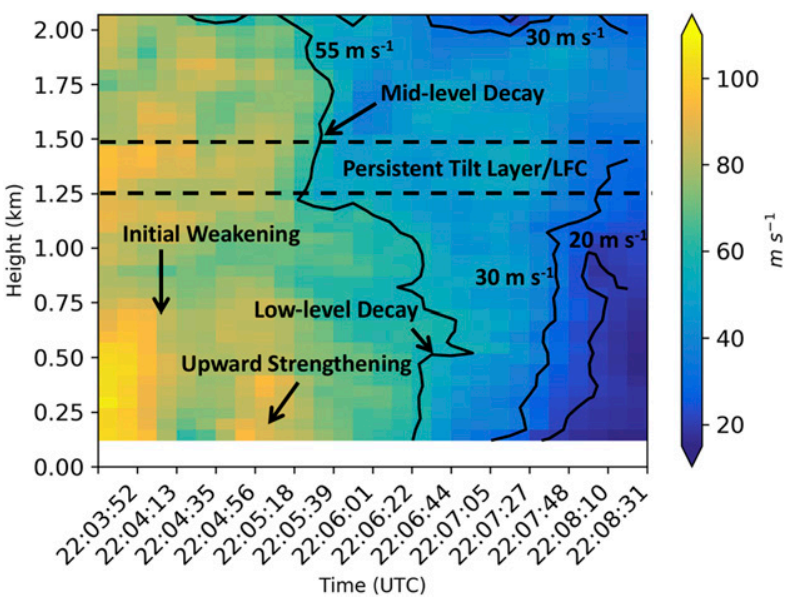

FIG. 5. Time-height plot of maximum $\Delta V\left(\mathrm{~m} \mathrm{~s}^{-1}\right)$ within the tornado. Overlaid are the 55,30 , and $20 \mathrm{~m} \mathrm{~s}^{-1} \Delta V$ contours. Note that sampling of tornado intensity was not continuous, but rather there is approximately $10.5 \mathrm{~s}$ between each estimate of $\Delta V$.

tornado whereas RaXPol had poor low-level coverage of the 24 May 2011 El Reno tornado during decay (Houser et al. 2015). Differential velocity decreased within the analyzed column below the $55 \mathrm{~m} \mathrm{~s}^{-1}$ threshold for tornado intensity noted by Houser et al. (2015) during the initial decay (Fig. 5). However, a funnel cloud was still present for approximately $1 \mathrm{~min}$ after this initial weakening (3:00-4:00; see Canadian tornado video URL cited above). The persistent funnel cloud coupled with $\Delta V>40 \mathrm{~m} \mathrm{~s}^{-1}$ led us to believe that this initial weakening was not the dissipation of the tornado. However, previous studies (e.g., Tanamachi et al. 2013; Wurman and Kosiba 2013) have examined tornadoes with similar intensity to the Canadian tornado at this stage of its life cycle that did not exhibit funnel clouds; therefore, a funnel cloud is not a necessary condition for a tornado owing to its dependency on both vortex intensity and water vapor pressure.

After a minute of marginal tornado intensity, the vortex decayed beginning around 2207:27 UTC in the lowest $1.25 \mathrm{~km}$ ARL while it maintained $\Delta V$ of $\sim 40 \mathrm{~m} \mathrm{~s}^{-1}$ above this altitude. Below $750 \mathrm{~m} \mathrm{ARL}$, the tornado weakened in an upward direction. Video of tornado decay (3:15-4:00; see Canadian tornado video URL cited above) also illustrated upward dissipation of the funnel cloud at this time. However, the upward dissipation of the funnel cloud may also have been the result of upward advection of drier air. Above $750 \mathrm{~m}$ ARL, the tornado dissipated nearly simultaneously (Fig. 5), similar to what was observed in the 24 May 2011 El Reno, Oklahoma, tornado at altitudes above $1 \mathrm{~km}$ ARL (Houser et al. 2015). The $\Delta V$ threshold of $30 \mathrm{~m} \mathrm{~s}^{-1}$ best captures the tornado decay based on the dissipation of the funnel cloud; however, the rapid decrease in $\Delta V$ from in excess of $40 \mathrm{~m} \mathrm{~s}^{-1}$ to less than $20 \mathrm{~m} \mathrm{~s}^{-1}$ in less than 30 s means that any threshold between 20 and $40 \mathrm{~m} \mathrm{~s}^{-1}$ (not shown) would also approximately discriminate between tornadic and nontornadic intensity. These lower $\Delta V$ thresholds for tornado criteria agree well with other previous work (e.g., Alexander and Wurman 2008; Marquis et al. 2012; Kosiba and Wurman 2013; French et al. 2013).

\section{b. Tornado tilt}

The Canadian, Texas, tornado became increasingly tilted through all depths beginning at 2205:39 UTC and lasting through tornado dissipation (Fig. 6a). The increase in tornado tilt corresponded with the initial stage of tornado decay in Fig. 5. Increase in tornado tilt was maximized in the $0.1-0.5-$ and $0.1-1.0-\mathrm{km}$ layers, where tilt increased from approximately $25^{\circ}$ to $55^{\circ}$ and from $35^{\circ}$ to $55^{\circ}$, respectively. The increase in tilt was the result of the low-level vortex becoming increasingly displaced to the west of the midlevel vortex (Fig. 6b). While the Canadian tornado at the lowest elevation angle (black) moved steadily westward, higher up, between 1 and $2 \mathrm{~km}$ ARL (red), the Canadian tornado looped cyclonically and moved only slightly westward during dissipation. This tornado motion likely resulted in the tornado becoming occluded as the low levels became displaced to the west of the mesocyclone above $1 \mathrm{~km}$ as well as to the west of the position of the rear-flank gust front (not shown).

The direction of tilt in the $0.1-2.0 \mathrm{~km}$ ARL $\left(0.5^{\circ}-20^{\circ}\right)$ layer was to the northeast for the entirety of the deployment (Fig. 7), which is similar to the $0-3-\mathrm{km}$ environmental wind shear vector (not shown). Similar northeastward tilt has been noted previously (e.g., Tanamachi et al. 2012, 2013; French et al. 2014) and appears to be a common orientation for supercellular tornadoes in the Northern Hemisphere. The tilt direction changed from toward the NNE to toward the ENE during the tornado decay period. This clockwise shift in tilt direction corresponded with the westward motion of the low-level vortex relative to the upper levels of the vortex (Fig. 6b). The largest change in tilt direction started at 2205:39 UTC (Fig. 7), when the first tornado decay period began (Fig. 5) and the aforementioned increase in tilt occurred.

The simultaneous RHIs collected by the AIR also allows for the interrogation of the vertical shape of the tornado in greater detail (Fig. 8). Early on in the deployment when the tornado was at its observed maximum diameter and intensity, the tornado was nearly upright with minimal vortex tilt below the cloud base (Figs. 8a,d). As previously mentioned, the tornado 


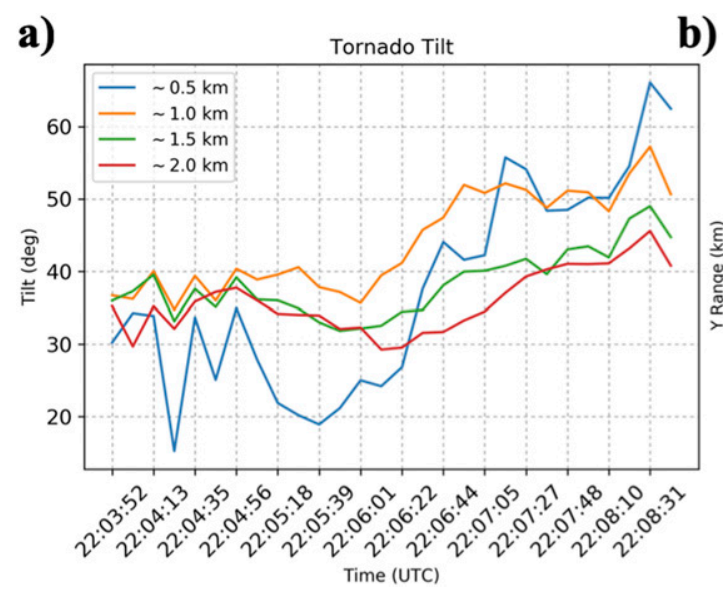

b) 4.5

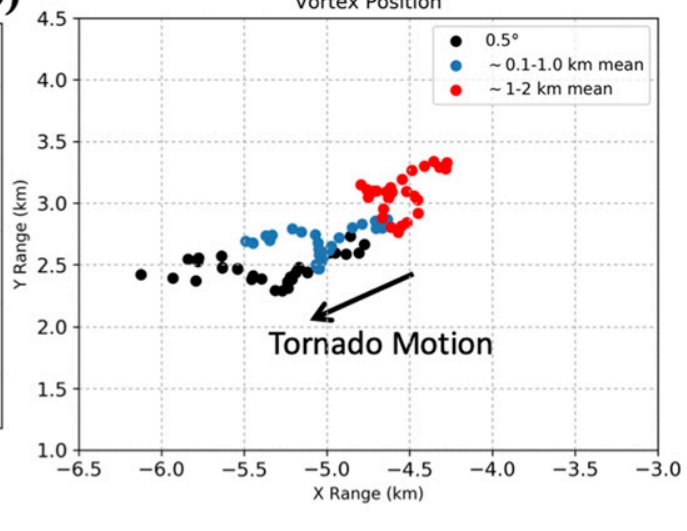

FIG. 6. (a) Tornado tilt $\left({ }^{\circ}\right)$ between the lowest elevation angle $(\sim 0.1 \mathrm{~km})$ and $0.5 \mathrm{~km}$ (blue), $1.0 \mathrm{~km}$ (orange), $1.5 \mathrm{~km}$ (green), and $2.0 \mathrm{~km}$ (red). (b) Tornado center at the lowest elevation angle (black) and mean tornado center in the $0.1-1.0-\mathrm{km}$ layer (blue) and 1.0-2.0-km layer (red). Storm motion is from right to left at all levels.

became increasingly tilted late in its life cycle (Figs. 8b,d). A rapid increase in tilt was observed between 400 and $700 \mathrm{~m}$ ARL during the 2206:01-2206:44 UTC period (Figs. 8c,d). The formation of the region of vortex tilt in excess of $70^{\circ}$ corresponded temporally with the downward tornado decay observed in Fig. 5 and was located at the bottom of the of the vertical layer where downward decay occurred. Interestingly, the layer with the largest tilt, between 400 and $700 \mathrm{~m}$ ARL, exhibited the slowest decrease in $\Delta V$ (Fig. 5) $)^{2}$ and has relatively high $\Delta V$ compared to the layer below with less tilt, opposite of the inverse relationship between vortex intensity and tornado tilt observed by French et al. (2014). Another feature of interest was a layer of persistent tilt $\left(40^{\circ}-50^{\circ}\right)$ above the cloud base between 1.25 and $1.5 \mathrm{~km}$ ARL. This region of persistent tilt also divided the aforementioned temporally separate mid- and low-level decay in Fig. 5. Speculation regarding the significance of this layer is reserved for section 4a. An additional layer of persistent tilt was located between 750 and $1000 \mathrm{~m}$ ARL, near the cloud base. At the beginning of the decay phase corresponding to the photograph in Fig. $8 \mathrm{~b}$, the region of tilt near the cloud base either disappeared or descended and merged with the aforementioned high-tilt region between 400 and $700 \mathrm{~m}$ ARL.

\section{c. Vertical cross sections}

A simultaneously collected RHI through the concentric WEHs (Fig. 9a) reveals that the inner bands of enhanced reflectivity were disconnected from any

\footnotetext{
${ }^{2}$ Note that the slowest decay occurring in the most tilted layer means that the downward decay may have been slower than what is presented because of biases owing to tornado geometry.
}

regions of higher reflectivity aloft and extended below the lowest observed elevation (Fig. 9b). Conversely, the outer bounds of the larger WEH were part of a continuous region of high reflectivity that extended through $20^{\circ}$ in elevation. While the outer WEC extended higher than the $750 \mathrm{~m}$ illustrated in Fig. 9b, the tornado tilts out of the RHI plane, precluding observation of the feature through a deeper layer. Regardless, the contrasting vertical structure of the WECs in the low levels supports the hypothesis that the two WECs represented different types of scatterers. It is speculated that the inner WEH comprised light debris that were lofted from the surface

$0^{\circ}$

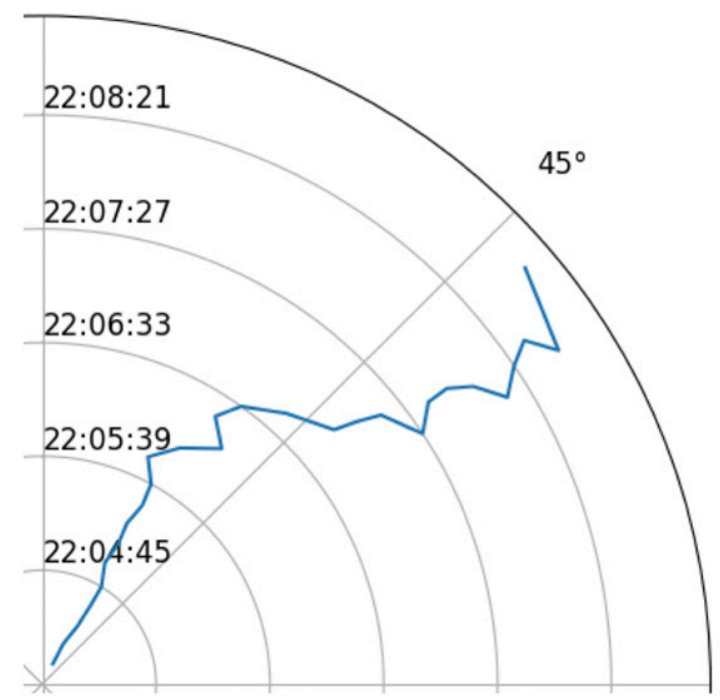

$90^{\circ}$

FIG. 7. Direction of vortex tilt between 0.1 and $2.0 \mathrm{~km}$ ARL in clockwise degrees from north. Radial axis is time in UTC. 

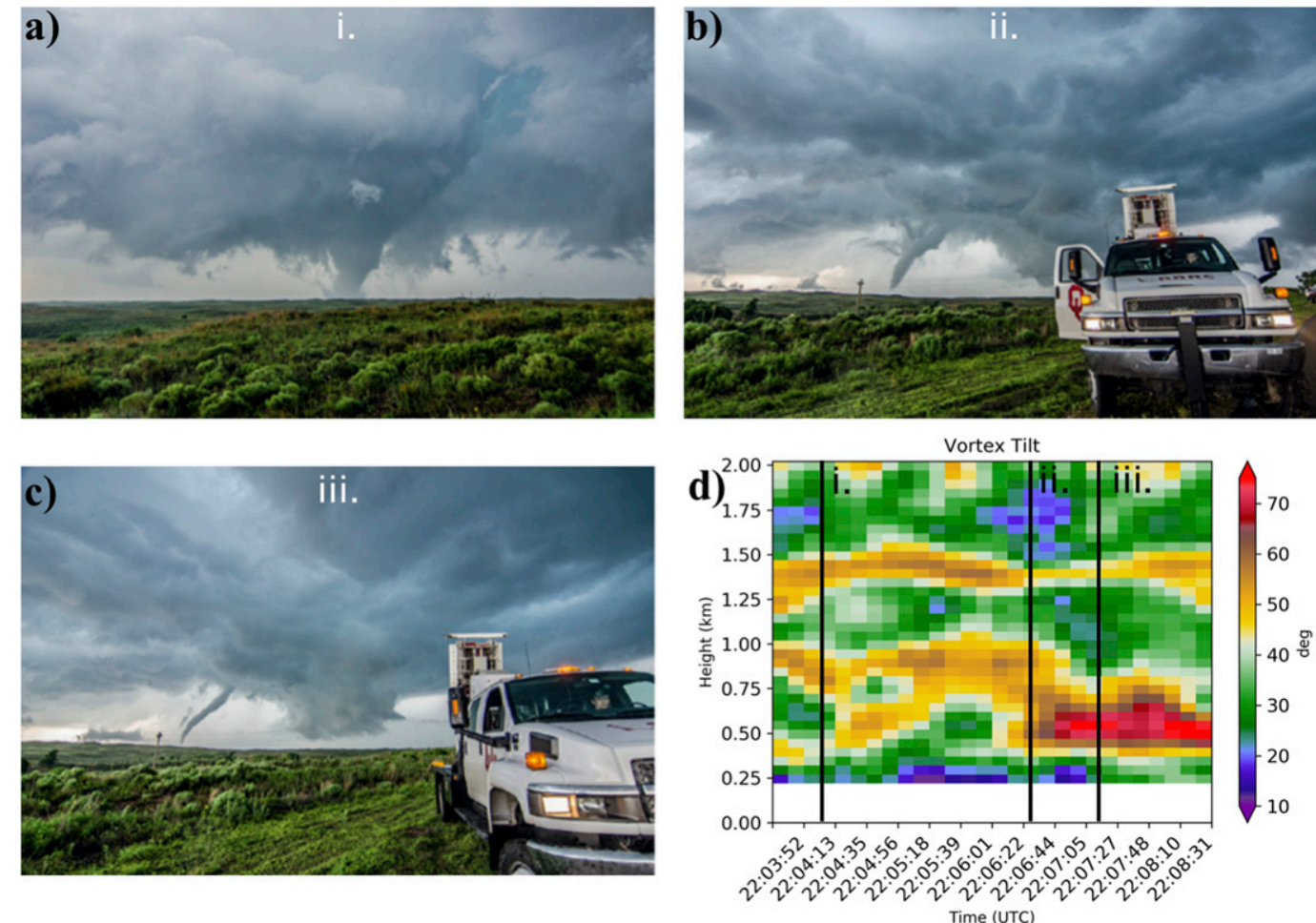

FIG. 8. Photographs at (a) 2204, (b) 2206, and (c) 2207 UTC and (d) a time-height plot of filtered vortex tilt $\left(^{\circ}\right)$. Vertical lines i, ii, and iii in (d) correspond with (a)-(c), respectively. Photographs adapted from Kurdzo et al. (2017).

and the outer WEH represented descending rainbands at the periphery of the tornado. However, in the absence of polarimetric data, this hypothesis cannot be confirmed.

To better observe the vertical structure of the WEH, azimuth height indicators (AHIs) consisting of a vertical cross section along a constant range are constructed (Fig. 10a). While these AHIs are not simultaneous, they only represent a span of $\sim 5 \mathrm{~s}$ of data, and therefore are comparable to traditional RHIs collected by mechanically steered radars. Because the Canadian tornado was tilted to the northeast (Fig. 7), this geometry better captures a deeper layer of the WEC along the direction of tornado tilt. However, the tapered nature of the WEC above $1.25 \mathrm{~km}$ ARL and the disappearance of the WEC above $1.5 \mathrm{~km}$ (Fig. 10b) are artifacts of the tornado tilting out of the AHI plane within the persistent tilt layer between
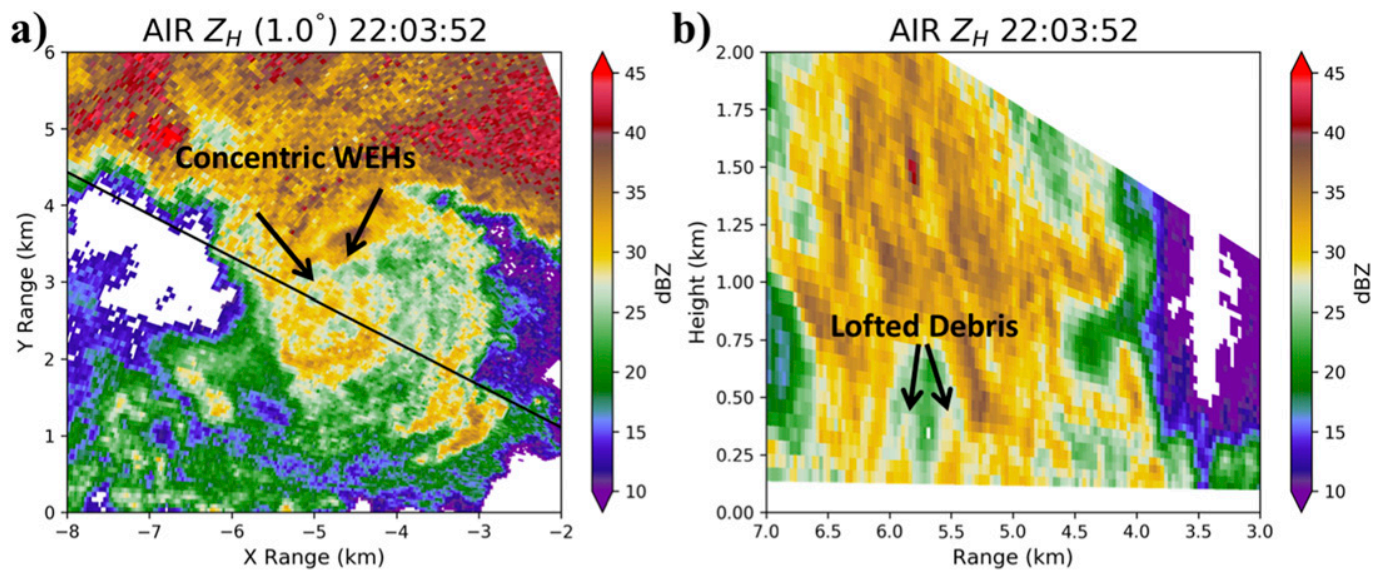

FIG. 9. (a) PPI plot of reflectivity (dBZ) at $1^{\circ}$ elevation and (b) RHI of reflectivity (dBZ) valid at 2203:52 UTC. Black line in (a) represents the location of the RHI in (b). 

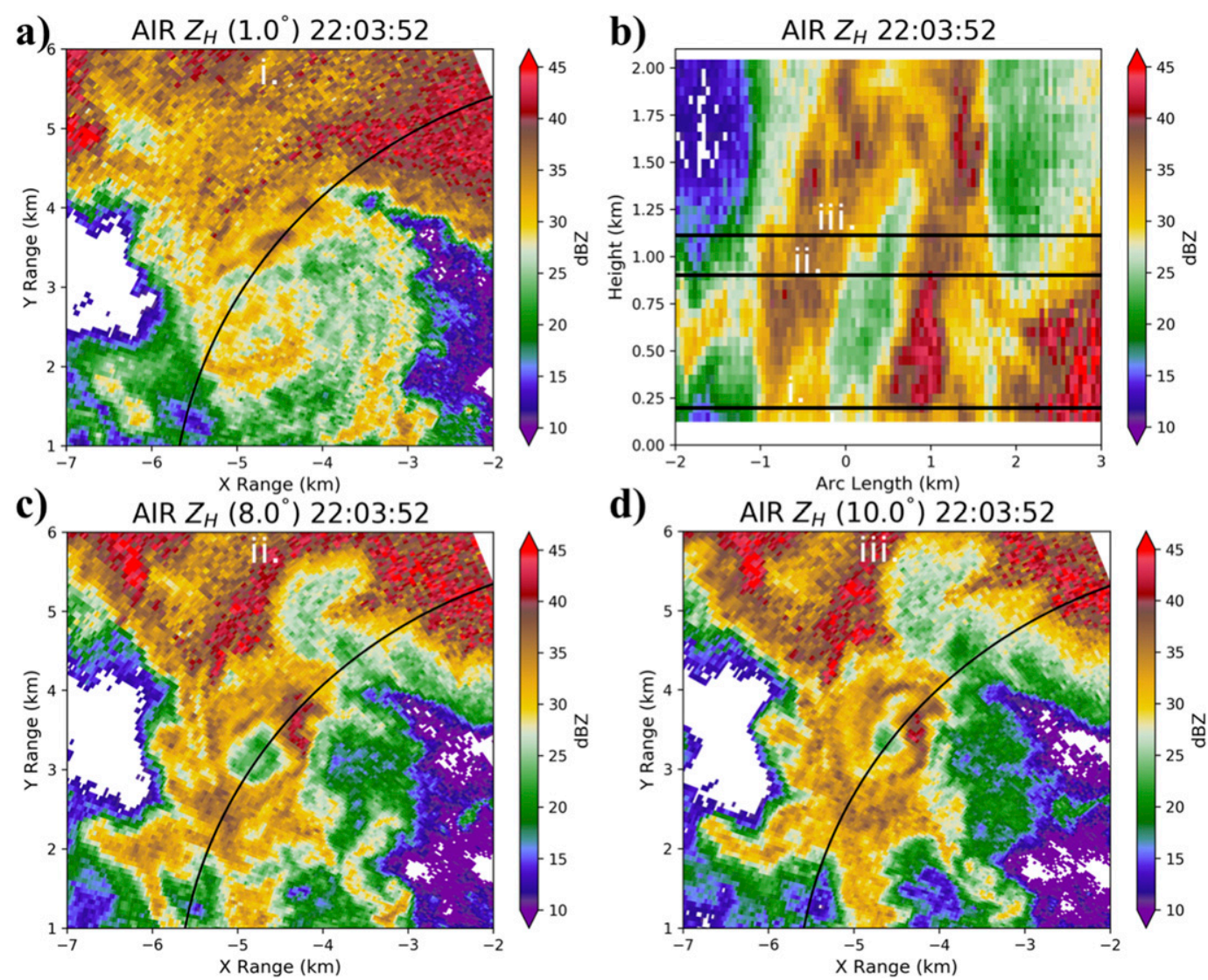

FIG. 10. (a),(c),(d) PPI plots of reflectivity $(\mathrm{dBZ})$ at $1^{\circ}, 8^{\circ}$, and $10^{\circ}$, respectively; and (b) AHI of reflectivity (dBZ) valid at 2203:52 UTC. Horizontal lines i, ii, and iii in (b) correspond with (a), (b), and (d), respectively. Black lines in (a), (c), and (d) represent the location of the AHI in (b).

1.25 and $1.5 \mathrm{~km}$ ARL. In contrast, the abrupt narrowing of the WEC at $1 \mathrm{~km}$ ARL is not an artifact of tornado tilt since the AHI bisects the WEH at its widest point beneath $1 \mathrm{~km}$ (Fig. 10c) and just above $1 \mathrm{~km}$ (Fig. 10d). While there was no observed vertical gradient in $\Delta V$ in this layer (Fig. 5), there was an appreciable narrowing of the RMW (Figs. 2f,h). Beneath the height of the abrupt narrowing, the WEC slightly broadened with height resulting a bulging structure similar to what was observed by Bluestein et al. (2007b) [cf. Fig. 13 in Bluestein et al. (2007b)].

As previously mentioned, the Canadian tornado became increasingly tilted late in its life cycle (Fig. 8). A simultaneous RHI was taken through the tornado (Fig. 11) near time ii in Figs. 8b,d. The tilt of the tornado at this time was $45^{\circ}-50^{\circ}$ from vertical in the layer between 400 and $750 \mathrm{~m}$ ARL. Differential velocity was computed in both the vertical (Fig. 11b) and horizontal (Figs. 11c,d) planes. As expected from a tornado that was tilted approximately $45^{\circ}$ from vertical, the magnitude of vertical shear was similar to the magnitude of horizontal shear with $\Delta V$ between 50 and $60 \mathrm{~m} \mathrm{~s}^{-1}$ depending on the choice of elevation angle for PPIs and radial for RHIs. The vertical shear in Fig. 11b is due to the tornado being partially tilted into the horizontal plane, which results in the RHI bisecting outbound velocities on the north side of the tornado in the low levels (Fig. 11c) and inbound velocities on the south side of the tornado aloft (Fig. 11d). The largest vertical gradient in Doppler velocity at $6 \mathrm{~km}$ in range was largely contained within the 400-700-m layer ARL where the tornado was also the most tilted (Fig. 8d). The horizontal vorticity associated with the tilted vortex was strong enough to centrifuge hydrometeors and cause a WEH to appear (Dowell et al. 2005) in the horizontal plane (Fig. 11a). The center of this WEH bisected the layer where the strongest vertical gradient in Doppler velocity was observed.

\section{Discussion}

\section{a. Persistent vortex tilt layer and tornado decay}

The persistent region of enhanced vortex tilt between 1.25 and $1.5 \mathrm{~km}$ ARL (Fig. 8d) coincided with the 

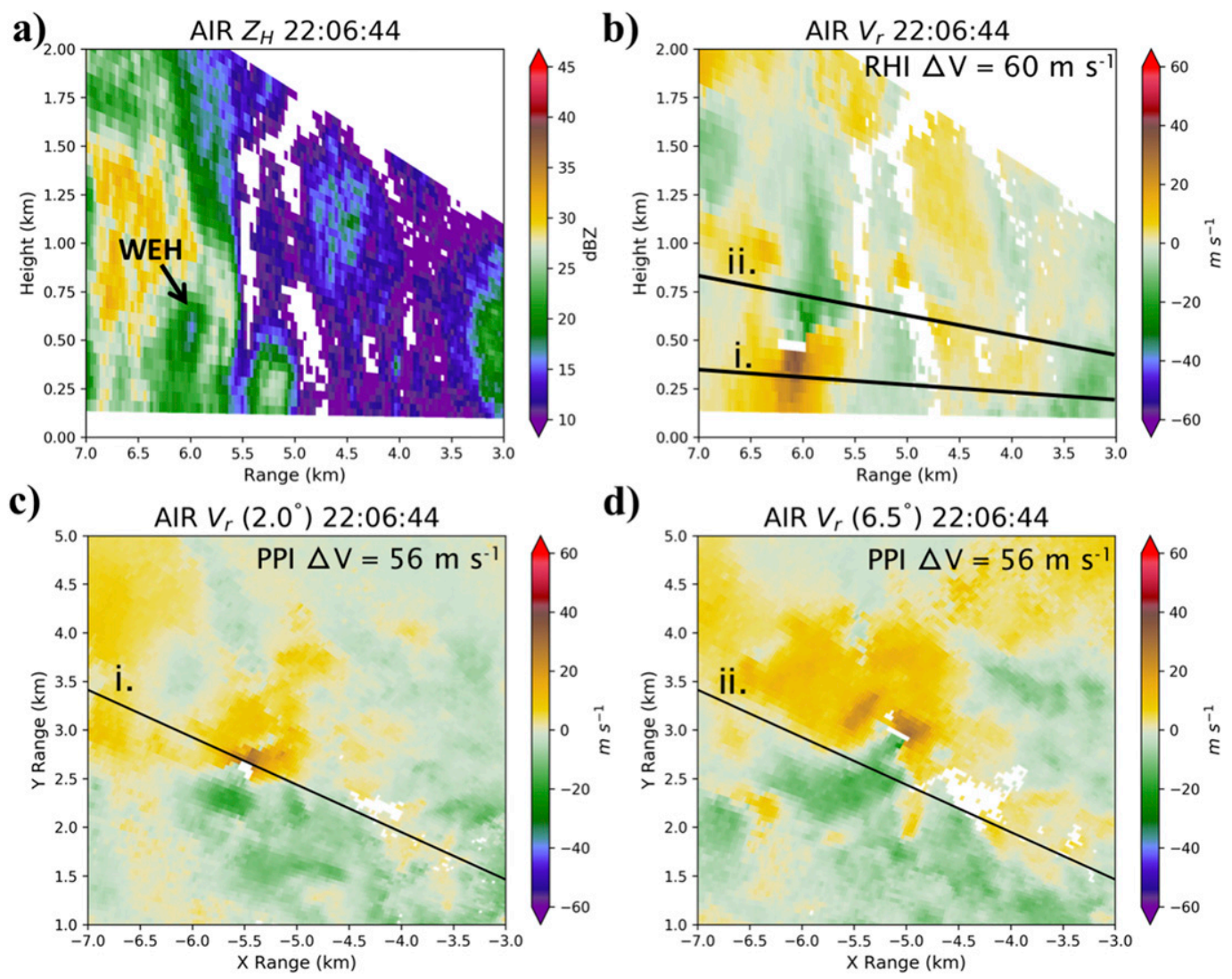

FIG. 11. RHI plots of (a) radial velocity $\left(\mathrm{m} \mathrm{s}^{-1}\right)$ and (b) reflectivity $(\mathrm{dBZ})$ and PPI plots of radial velocity $\left(\mathrm{m} \mathrm{s}^{-1}\right)$ at (c) $2^{\circ}$ and (d) $6.5^{\circ}$ elevation valid at 2206:44 UTC. The tornado is very tilted through the 400-700-m layer (see Fig. 8d) as evidenced by the shift in vortex position between (c) and (d). Strong horizontal vorticity is evident through this layer with slightly larger $\Delta V$ in the RHI scan compared to the PPI scans. Black lines $i$ and ii in (b) correspond with the elevation angles in (c) and (d), respectively. Black lines in (c) and (d) correspond with the location of the RHIs in (a) and (b), respectively.

level that separated the temporally displaced mid- and low-level vortex decay near the end of the Canadian tornado life cycle (Fig. 5). Additionally, the maximum tornado intensity observed at the beginning of the deployment as well as the brief restrengthening of the tornado that occurred shortly thereafter was confined to within the lowest $1 \mathrm{~km}$ (Fig. 5). It is hypothesized from this body of circumstantial evidence that the vertical layer around $\sim 1.25 \mathrm{~km}$ ARL was particularly relevant to the Canadian tornado.

The Dodge City, Kansas, 0000 UTC sounding was launched approximately $1 \mathrm{~h}$ after the Canadian tornado occurred, and despite the approximately $200 \mathrm{~km}$ that separate the locations, the surface conditions at Dodge City (DDC) were nearly identical to those in Canadian, Texas, at the time of the tornado (Fig. 12a). Additionally, environmental temperatures at 700 (Fig. 12b) and $500 \mathrm{mb}(1 \mathrm{mb}=1 \mathrm{hPa})$ (Fig. $12 \mathrm{c})$ were also similar at DDC and Canadian, Texas, and the regional environment was relatively uniform. Thus, it is assumed that the DDC sounding (Fig. 12b) was at least somewhat representative of the environmental thermodynamic profile in Canadian, Texas. The level of free convection (LFC) at DDC was at approximately $760 \mathrm{mb}$, corresponding to $\sim 1500 \mathrm{~m}$ above ground level (AGL) at the sounding site. Replacing the surface conditions of the DDC sounding with the ASOS observations in Canadian, Texas, at the time of the tornado (not shown) lowers the LFC to $800 \mathrm{mb}$ or $1250 \mathrm{~m} \mathrm{ARL}$, which is within the layer of enhanced vortex tilt.

The transition from forced to free ascent by parcels within the tornado may have caused a change in parcel trajectory and might explain the tilted nature of the vortex in this layer, especially given that the layer between 1 and $2 \mathrm{~km}$ exhibited considerable environmental wind shear (Fig. 12d). In this scenario, ascent, which was forced beneath the LFC, would have been slower than above the LFC where parcels were positively buoyant. As a result, more horizontal advection would 

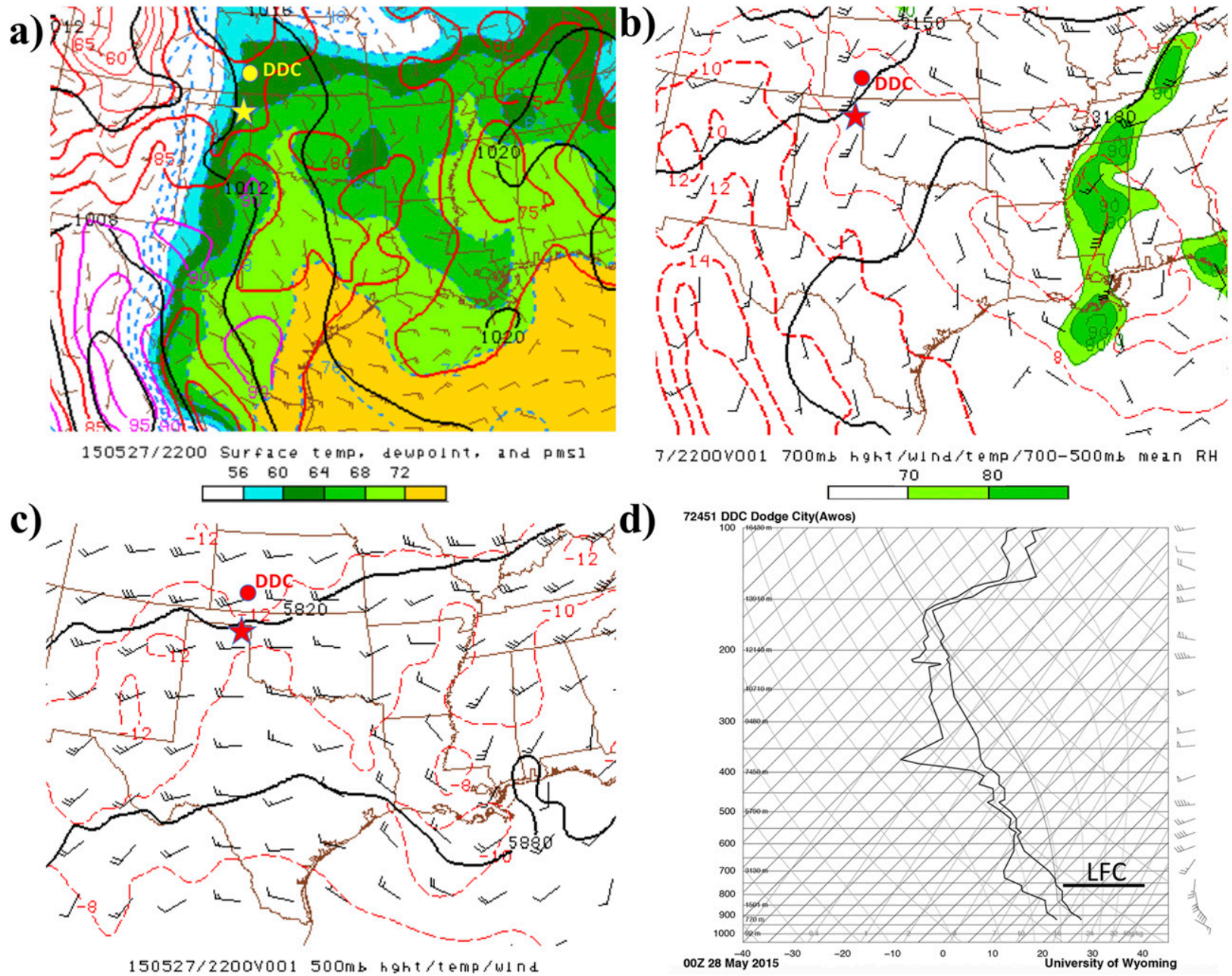

FIG. 12. Storm Prediction Center mesoanalysis of (a) surface temperature (red lines, ${ }^{\circ} \mathrm{F}$ ), mean sea level pressure (black lines, mb), and dewpoint temperature (shaded, ${ }^{\circ} \mathrm{F}$ ), (b) 700-mb height (black lines, m), temperature (red lines, ${ }^{\circ} \mathrm{C}$ ), and 700-500-mb mean RH (shaded, \%), and (c) 500-mb height (black lines, m) and temperature (red lines, ${ }^{\circ} \mathrm{C}$ ) valid at 2200 UTC 27 May 2015 . The star indicates the location of Canadian, TX, and the circle indicates the location of Dodge City, KS. Archived mesoananalyses are available online at http://www.spc.noaa.gov/exper/ma_archive/. (d) Skew $T$-log $p$ diagram of the vertical sounding launched at Dodge City, KS, valid at 0000 UTC 28 May 2015. Archived soundings are available online at http://weather.uwyo.edu/upperair/sounding.html.

have occurred beneath the LFC than above it. The vertical gradient in vertical velocity necessary for increased tilt in this layer is similar to what was inferred by French et al. (2014) when discussing the increased vertical vorticity stretching that may occur near the LFC. Differential horizontal advection in this layer would be enhanced if the near-storm environment beneath the LFC were particularly stable. A stable layer would also have contributed to the observed vertical discontinuity in tornado decay similar to what was observed by Houser et al. (2015). Within the stable layer, parcels would not be accelerated upward by the buoyancy force, which in turn weakens vertical gradients in vertical velocity and subsequently limits the stretching of vertical vorticity. If negatively buoyant air were to be ingested into the updraft, within and above a stable layer the vertical gradient in vertical velocity could even become negative, rapidly reducing vortex strength through horizontal divergence. However, a near-storm sounding would be necessary to assess whether a small stable layer was present.

Changes in inflow characteristics associated with tornado occlusion may impact vortex strength above the LFC on a different time scale than below the LFC. The gradual, downward vortex weakening in Fig. 5 might first occur just above the LFC where the buoyancy force plays an important role in accelerating parcels and stretching vorticity. Vortex decay below the LFC may lag midlevel decay because ascent is forced by a dynamic pressure gradient force that is modulated by midlevel 
vortex strength. This possible explanation would be in agreement with the tornado occlusion mechanism for tornado decay hypothesized in French et al. (2014), where tornadoes first weaken just above the level of occlusion and then dissipate in an "inside out" fashion. Additionally, the 5 June 2009 Goshen County, Wyoming, tornado was observed to intensify much more rapidly above the LFC than below the LFC (French et al. 2013), which further supports the theory that the LFC demarks a boundary in tornado structure and evolution.

While the LFC appears to separate two dissipation modes, there are many additional factors that may contribute to tornado intensity. A comparison of tornado diameter to tornado intensity (Fig. 13) reveals that tornado intensity was anticorrelated with the distance between the location of maximum and minimum Doppler velocity within the tornado. During the brief restrengthening period between 2204:13 and 2205:18 UTC, tornado diameter decreased from approximately $700 \mathrm{~m}$ to between 100 and $200 \mathrm{~m}$. The tightening of the vortex was confined to the lowest $750 \mathrm{~m}$ ARL, the same depth over which tornado intensity increased. Conversely, the near-simultaneous weakening of the tornado above $1250 \mathrm{~m} \mathrm{ARL}$ at 2205: 28 UTC occurred at the same time vortex diameter doubled from $\sim 300-400$ to $\sim 700-800 \mathrm{~m}$ within the same vertical layer. Tornado intensity at this time approximately halved from $\Delta V$ of near $90 \mathrm{~m} \mathrm{~s}^{-1}$ to $\Delta V$ less than $50 \mathrm{~m} \mathrm{~s}^{-1}$, which implies that angular momentum remained relatively constant during this weakening period. Finally, between 500 and $1000 \mathrm{~m}$ ARL, downward broadening of the tornado coincided with downward decay. The tornado widened nearly simultaneously in the lowest $500 \mathrm{~m}$ at 2206:22 UTC, approximately at the same time the tornado weakened within the same layer. While it is expected that a decrease in overall angular momentum occurred during tornado decay (Rasmussen and Straka 2007; Atkins et al. 2012), it appears that over short time periods the conservation of angular momentum at least partially contributes to changes in the magnitude of $\Delta V$ as the Canadian tornado underwent changes in diameter. The inverse relationship between the magnitude of $\Delta V$ and the radius of maximum winds is consistent with the behavior of the 5 June 1999 Bassett, Nebraska, tornado (Bluestein et al. 2003) except in this case the relationship was investigated at each elevation angle through a $2-\mathrm{km}$ depth and not just a single level. However, the behavior of the Canadian tornado is dissimilar to the 15 May 1999 Stockton, Kansas, tornado where both tangential velocity and tornado diameter decreased simultaneously during decay
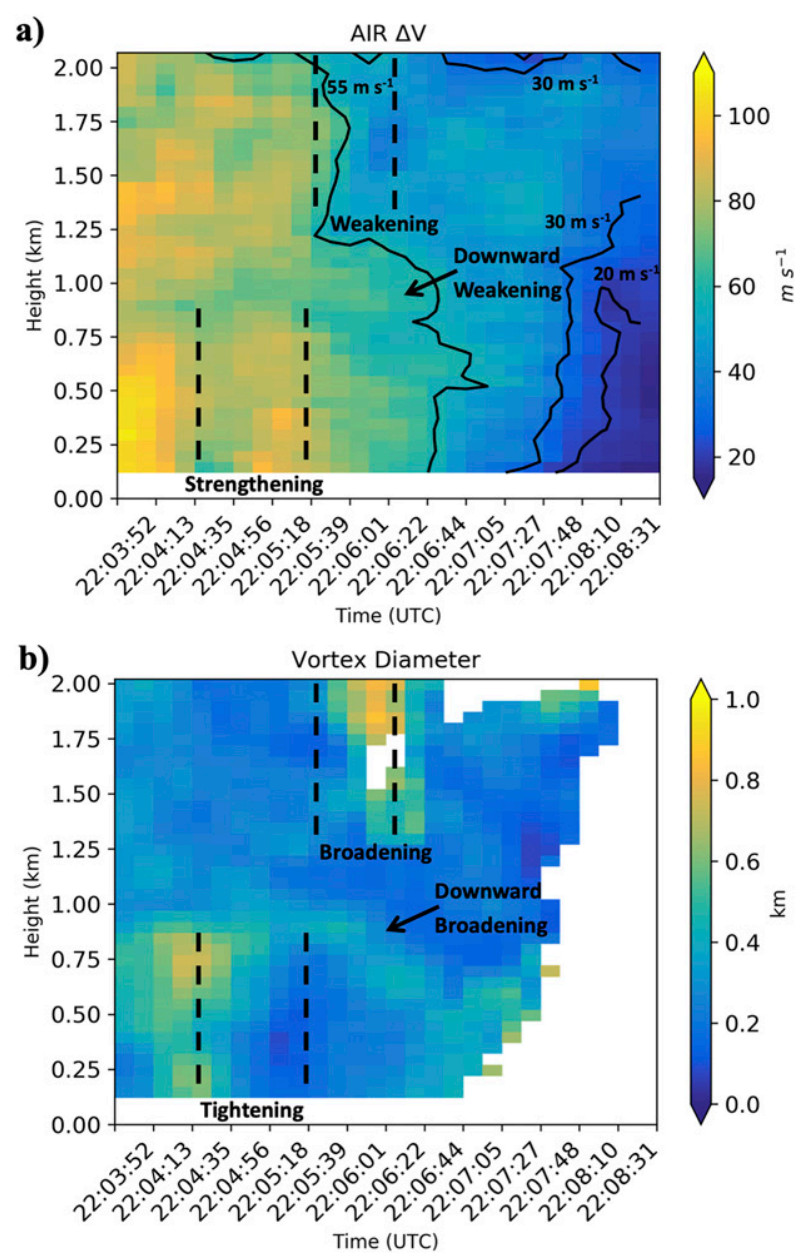

FIG. 13. Time-height plots of (a) maximum $\Delta V\left(\mathrm{~m} \mathrm{~s}^{-1}\right)$ as in Fig. 5 and (b) the distance $(\mathrm{km})$ separating maximum inbound and maximum outbound velocities used to calculate $\Delta V$ in (a). Vortex diameter is thresholded on $\Delta V$ beneath $40 \mathrm{~m} \mathrm{~s}^{-1}$ where diameter calculations became much noisier.

(Tanamachi et al.2007), illustrating a range of late life cycle tornado behaviors.

\section{b. Vertical correlation in vortex intensity}

Differential velocity $(\Delta V)$ at all heights was highly correlated with $\Delta V$ at the lowest analysis level at zero lag for the deployment period (Fig. 14). High correlation at lag 0 suggests that changes in vortex intensity occurred largely simultaneously in the vertical. Values of correlation were greater than 0.97 for all heights in the analysis. The linear decrease in correlation throughout most of the analysis signifies that correlation with near-surface intensity was inversely related to the vertical displacement from the surface, likely as intensity changes aloft became slightly less in phase with changes near the surface. However, correlation at nonzero lags (not shown) was approximately 0.05 lower with each 


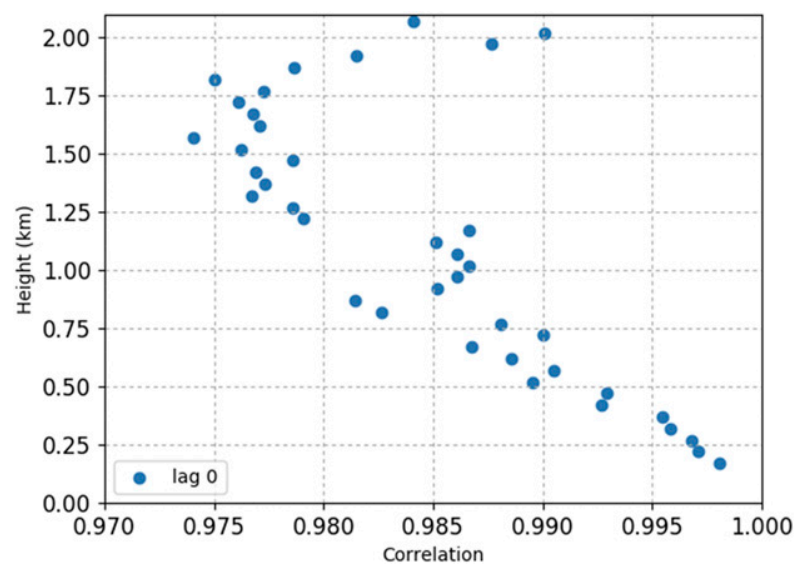

FIG. 14. Cross correlation at lag 0 of $\Delta V$ at each height $(\mathrm{km})$ with the $0.5^{\circ}$ scan. The calculation was performed over the 2203:52-2207: 37 UTC time period when $\Delta V$ exceeded $40 \mathrm{~m} \mathrm{~s}^{-1}$ throughout the majority of the observed depth. High correlation at lag 0 suggests that changes in vortex intensity occur largely simultaneously in the vertical.

increasing lag. ${ }^{3}$ This further suggests that simultaneous changes in intensity were more prevalent than directional changes in intensity (i.e., upward or downward strengthening or weakening of the vortex) in the Canadian tornado similar to what was observed during the majority of the 24 May 2011 El Reno case (Houser et al. 2015). Recall that there was one noted instance of upward tornado strengthening in the Canadian tornado (Fig. 5), but the restrengthening was brief and above the lowest few analysis levels the intensification occurred simultaneously rather than upward in direction. As a result, no signal was found at negative lags and therefore it is not shown. Additionally, the Canadian tornado was observed to decay in a downward direction between 400 and $1250 \mathrm{~m}$ ARL (Fig. 5); however, analysis of correlation at positive lags was inconclusive and are not included. It is likely that the relatively small number of data points that encompassed the observed upward and downward changes in vortex intensity caused their signal to be washed out by the highly correlated nature of the vortex over the length of the full deployment. The directional changes in vortex intensity are important to understanding the behavior of the Canadian tornado during decay, but they do not characterize tornado behavior for the majority of observed period.

The high correlation of vortex intensity at all heights with the low-level vortex in the Canadian tornado

\footnotetext{
${ }^{3}$ In this case, a negative lag would mean that changes near the surface preceded changes aloft (i.e., upward strengthening/weakening) and a positive lag means that changes aloft preceded changes near the surface (downward strengthening/weakening).
}

contrasts with other recent high-temporal observations of tornadoes. French et al. (2014) noted that low-level vortex intensity in the 5 June 2009 Goshen County, Wyoming, EF2 tornado was often anticorrelated with midlevel intensity. This was largely due to the oscillatory nature of low-level vortex strength. However, French et al. (2014) were comparing average tornado intensity below $2 \mathrm{~km}$ with average intensity above $2 \mathrm{~km}$, which sometimes extended above $5 \mathrm{~km}$ ARL, whereas all of the observations in the Canadian case were below $2 \mathrm{~km}$. Similar to the Goshen County tornado, the 16 May 2015 Tipton, Oklahoma, tornado also exhibited periodic changes in low-level vortex intensity, which often decorrelated vortex intensity in the lowest $500-700 \mathrm{~m}$ from vortex intensity above $700 \mathrm{~m}$ (Mahre et al. 2018). Periodic changes in low-level tornado intensity have also been observed by Wurman et al. (2013) using hightemporal resolution mobile radar data. Additionally, the Tipton tornado experienced one instance of pronounced upward tornado intensification, although this may be due to debris-induced biases (Mahre et al. 2018). The Canadian tornado did not exhibit strong periodicity in low-level vortex intensity during the observed period; however, these observations were during the latemature to dissipation stages whereas the Tipton observations were during the mature stage, so caution is required when comparing the two cases. Perhaps there is some mechanism for periodic oscillations in tornado intensity that is less likely to occur late in the tornado life cycle (e.g., because the tornado and mesocyclone are less vertically stacked). However, it can be concluded that during the late mature and decay phases of the Canadian tornado, changes in vortex intensity in the lowest $2 \mathrm{~km}$ were largely nonperiodic and were highly correlated with tornado intensity at the lowest analysis level.

\section{Conclusions}

On 27 May 2015, the AIR collected 4.5 min of sector volumes with 5.5-s temporal resolution during the latemature and decay stages of the Canadian, Texas, tornado. At the beginning of the deployment, maximum $\Delta V$ within the tornado was observed to be $110 \mathrm{~m} \mathrm{~s}^{-1}$. At this time, the tornado vortex widened from a small diameter vortex near the surface to a wide vortex with weak Doppler velocities in its core aloft and then back to a small diameter vortex above the cloud base. Broken rings of enhanced spectrum width at the radius of maximum winds, and regions of enhanced shear along the zero isodop were also observed, suggesting that the Canadian tornado initially had a multiple-vortex structure. Additionally, small-scale vortices were observed to 
exit the tornado and translate eastward beyond the RMW, each of which went through brief periods of intensification after being shed.

A weakening of the vortex occurred soon after the beginning of the dataset with $\Delta V$ decreasing from 110 to $80 \mathrm{~m} \mathrm{~s}^{-1}$ in less than $30 \mathrm{~s}$. A brief, bottom-up intensification of the Canadian tornado occurred following the weak period, coinciding with a narrowing of the tornado. The bottom-up intensification is similar to what has been previously noted by French et al. (2014) and Mahre et al. (2018), except observed here near the decay of the tornado. After the brief reintensification, the largest weakening of the tornado occurred. During this period, $\Delta V$ decreased to $40 \mathrm{~m} \mathrm{~s}^{-1}$.

The decay of the vortex first occurred simultaneously in the column above $1.25 \mathrm{~km}$ ARL and dissipation progressed in a downward direction over the next minute. An increase in tornado diameter occurred simultaneously with the observed decreases in $\Delta V$. The downward dissipation is similar to the "inside out" decay that was noted in French et al. (2014) and Houser et al. (2015) with the exception that the top half of the hypothesized inside out decay occurred above what the AIR observed in the Canadian case and this study includes observations in the lowest $1000 \mathrm{~m}$ unlike in Houser et al. (2015). Additionally, tornado decay occurred much more rapidly than was noted in French et al. (2014) and occurred in multiple modes (i.e., downward decay between 400 and $1250 \mathrm{~m}$, simultaneous decay between 150 and $400 \mathrm{~m}$, and decay in the lowest $150 \mathrm{~m}$ slightly preceding decay between 150 and $400 \mathrm{~m}$ ).

Apart from the brief upward intensification and downward decay periods, vortex intensity throughout the analyzed depth was highly correlated with intensity at the lowest analysis level and changes in intensity occurred nearly simultaneously in the vertical. The largely simultaneous vertical changes in vortex intensity were similar to what was observed in the 24 May 2011 El Reno, Oklahoma, tornado (Houser et al. 2015), but dissimilar to the anticorrelated low-level and midlevel tornado strength exhibited by the 5 June 2009 Goshen County, Wyoming, tornado (French et al. 2014) and the 16 May 2015 Tipton, Oklahoma, tornado (Mahre et al. 2018).

During decay, the Canadian tornado also became increasingly tilted in the low levels. The increase in tilt is the result of the low levels of the tornado becoming increasingly displaced to the west of the vortex above $1 \mathrm{~km}$, which potentially resulted in the tornado becoming occluded. Additionally, a persistent region of enhanced tilt was noted between 1.25 and $1.5 \mathrm{~km}$ ARL throughout the entire deployment. This height was the same that separated the midlevel and low-level decay at the end of the Canadian tornado life cycle, and roughly corresponds with the level of free convection, which may help explain both the enhanced tilt and early vortex decay in this region.

While the Canadian tornado is only one case in a growing list of high-temporal resolution tornado observations, it illustrates how rapidly tornado structure can change. Additionally, when considered alongside other recent high-temporal tornado datasets, the Canadian case also exemplifies the diversity of tornado behavior that exists within even a small sample of cases. While similarities are noted between the behavior of the Canadian tornado and tornadoes in other high-temporal datasets, many differences between the tornadoes were highlighted in this case. More high-temporal observations are needed in order to properly document the range of tornado behavior at short time scales and begin to understand the mechanisms that drive different rapid tornado evolutionary modes. It is our hope that a C-band, dual-polarimetric version of the AIR currently under development (PAIR; Salazar-Cerreño et al. 2017) will facilitate future high-temporal resolution observations of tornadoes in addition to providing information on the evolution of tornadic debris and hydrometeor distributions in supercells.

Acknowledgments. This study was supported by the National Science Foundation under Grants AGS1303685 and AGS-1823478. The authors thank Javier Lujan and Andrew Byrd for continued assistance with AIR fieldwork, as well as Feng Nai for help processing the data. We thank the ARRC engineering staff for continued upkeep of the AIR. The authors would also like to thank David Reimer for providing the supplemental video used as a reference in our analyses. Finally, the authors would like to thank the three anonymous reviewers for their contributions to improving all aspects of this paper.

\section{REFERENCES}

Alexander, C., and J. Wurman, 2008: Updated mobile radar climatology of supercell tornado structure and dynamics. 24th Conf. on Severe Local Storms, Savannah, GA, Amer. Meteor. Soc., 19.4, https://ams.confex.com/ams/24SLS/techprogram/ paper_141821.htm.

Atkins, N. T., A. McGee, R. Ducharme, R. M. Wakimoto, and J. Wurman, 2012: The LaGrange tornado during VORTEX2. Part II: Photogrammetric analysis of the tornado combined with dual-Doppler radar data. Mon. Wea. Rev., 140, 29392958, https://doi.org/10.1175/MWR-D-11-00285.1.

Bluestein, H. B., and A. Pazmany, 2000: Observations of tornadoes and other convective phenomena with a mobile, 3-mm wavelength, Doppler radar: The spring 1999 field experiment. Bull. 
Amer. Meteor. Soc., 81, 2939-2951, https://doi.org/10.1175/ 1520-0477(2000)081<2939:OOTAOC>2.3.CO;2.

, W.-C. Lee, M. Bell, C. C. Weiss, and A. L. Pazmany, 2003: Mobile Doppler radar observations of a tornado in a supercell near Bassett, Nebraska, on 5 June 1999. Part II: Tornado-vortex structure. Mon. Wea. Rev., 131, 2968-2984, https://doi.org/ 10.1175/1520-0493(2003)131<2968:MDROOA > 2.0.CO;2.

, M. M. French, R. L. Tanamachi, S. Frasier, K. Hardwick, F. Junyent, and A. Pazmany, 2007a: Close-range observations of tornadoes in supercells made with a dual-polarization, X-band, mobile Doppler radar. Mon. Wea. Rev., 135, 15221543, https://doi.org/10.1175/MWR3349.1.

, C. C. Weiss, M. M. French, E. M. Holthaus, R. L. Tanamachi, S. Frasier, and A. L. Pazmany, 2007b: The structure of tornadoes near Attica, Kansas on 12 May 2004: High-resolution, mobile, Doppler radar observations. Mon. Wea. Rev., 135, 475-506, https://doi.org/10.1175/MWR3295.1.

— M. French, I. PopStefanija, R. Bluth, and J. Knorr, 2010: A mobile, phased-array Doppler radar for the study of severe convective storms. Bull. Amer. Meteor. Soc., 91, 579-600, https://doi.org/10.1175/2009BAMS2914.1.

Dowell, D. C., C. R. Alexander, J. M. Wurman, and L. J. Wicker, 2005: Centrifuging of hydrometeors and debris in tornadoes: Radar-reflectivity patterns and wind-measurement errors. Mon. Wea. Rev., 133, 1501-1524, https://doi.org/10.1175/ MWR2934.1.

French, M., H. Bluestein, I. PopStefanija, C. Baldi, and R. Bluth, 2013: Reexamining the vertical development of tornadic vortex signatures in supercells. Mon. Wea. Rev., 141, 4576-4601, https://doi.org/10.1175/MWR-D-12-00315.1.

,,,--- , and $-, 2014:$ Mobile, phased-array, Doppler radar observations of tornadoes at X band. Mon. Wea. Rev., 142, 1010-1036, https://doi.org/10.1175/MWR-D13-00101.1.

Gall, R. L., 1983: A linear analysis of the multiple vortex phenomenon in simulated tornadoes. J. Atmos. Sci., 40, 20102024, https://doi.org/10.1175/1520-0469(1983)040<2010: ALAOTM $>2.0 . \mathrm{CO} ; 2$.

Houser, J., H. Bluestein, and J. Snyder, 2015: Rapid-scan, polarimetric, Doppler radar observations of tornadogenesis and tornado dissipation in a tornadic supercell: The "El Reno, Oklahoma" storm of 24 May 2011. Mon. Wea. Rev., 143, 26852710, https://doi.org/10.1175/MWR-D-14-00253.1.

Houser, J. L., H. B. Bluestein, and J. Snyder, 2016: A finescale radar examination of the tornadic debris signature and weakecho reflectivity band associated with a large, violent tornado. Mon. Wea. Rev., 144, 4101-4130, https://doi.org/10.1175/MWRD-15-0408.1.

Isom, B., and Coauthors, 2013: The Atmospheric Imaging Radar: Simultaneous volumetric observations using a phased array weather radar. J. Atmos. Oceanic Technol., 30, 655-675, https://doi.org/10.1175/JTECH-D-12-00063.1.

Kosiba, K. A., and J. M. Wurman, 2013: The three-dimensional structure and evolution of a tornado boundary layer. Wea. Forecasting, 28, 1552-1561, https://doi.org/10.1175/WAF-D13-00070.1.

Kurdzo, J. M., B. L. Cheong, R. D. Palmer, G. Zhang, and J. Meier, 2014: A pulse compression waveform for improved-sensitivity weather radar observations. J. Atmos. Oceanic Technol., 31, 2713-2731, https://doi.org/10.1175/JTECH-D-13-00021.1.

_ D. J. Bodine, B. L. Cheong, and R. D. Palmer, 2015: Hightemporal resolution polarimetric X-band Doppler radar observations of the 20 May 2013 Moore, Oklahoma, tornado.
Mon. Wea. Rev., 143, 2711-2735, https://doi.org/10.1175/ MWR-D-14-00357.1.

— tornadoes with the Atmospheric Imaging Radar. Bull. Amer. Meteor. Soc., 98, 915-935, https://doi.org/10.1175/BAMS-D15-00266.1.

Lewellen, D. C., W. S. Lewellen, and J. Xia, 2000: The influence of a local swirl ratio on tornado intensification near the surface. J. Atmos. Sci., 57, 527-544, https://doi.org/10.1175/15200469(2000)057<0527:TIOALS > 2.0.CO;2.

Mahre, A., J. M. Kurdzo, D. J. Bodine, C. B. Griffin, R. D. Palmer, and T.-Y. Yu, 2018: Analysis of the 16 May 2015 Tipton, Oklahoma, EF-3 tornado at high spatiotemporal resolution using the Atmospheric Imaging Radar. Mon. Wea. Rev., 146, 2103-2124, https://doi.org/10.1175/MWR-D-17-0256.1.

Marquis, J., Y. Richardson, P. Markowski, D. Dowell, and J. Wurman, 2012: Tornado maintenance investigated with high-resolution dual-Doppler and EnKF analysis. Mon. Wea. Rev., 140, 3-27, https://doi.org/10.1175/MWR-D-11-00025.1.

, J. Wurman, K. Kosiba, and P. Robinson, 2016: An investigation of the Goshen County, Wyoming, tornadic supercell of 5 June 2009 using EnKF assimilation of mobile mesonet and radar observations collected during VORTEX2. Part II: Mesocyclone-scale processes affecting tornado formation, mainenance, and decay. Mon. Wea. Rev., 144, 34413463, https://doi.org/10.1175/MWR-D-15-0411.1.

Mead, J., G. Hopcraft, S. J. Frasier, B. D. Pollar, C. D. Cherry, D. H. Schaubert, and R. E. McIntosh, 1998: A volumeimaging radar wind profiler for atmospheric boundary layer turbulence studies. J. Atmos. Oceanic Technol., 15, 849-859, https:// doi.org/10.1175/1520-0426(1998)015<0849:AVIRWP>2.0.CO;2.

Pazmany, A., J. Mead, H. Bluestein, J. Snyder, and J. Houser, 2013: A mobile rapid-scanning X-band polarimetric (RaXPol) Doppler radar system. J. Atmos. Oceanic Technol., 30, 13981413, https://doi.org/10.1175/JTECH-D-12-00166.1.

Rasmussen, E., and J. Straka, 2007: Evolution of low-level angular momentum in the 2 June 1995 Dimmitt, Texas, tornado cyclone. J. Atmos. Sci., 64, 1365-1378, https://doi.org/10.1175/ JAS3829.1.

Rotunno, R., 1978: A note on the stability of a cylindrical vortex sheet. J. Fluid Mech., 87, 761-771, https://doi.org/10.1017/ S0022112078001871.

Salazar-Cerreño, J. L., and Coauthors, 2017: Development of a mobile C-band polarimetric atmospheric imaging radar (PAIR). Special Symp. on Meteorological Observations and Instrumentation, Seattle, WA, Amer. Meteor. Soc., 1B.1, https://ams.confex.com/ ams/97Annual/webprogram/Paper308655.html.

Snyder, J., and H. Bluestein, 2014: Some considerations for the use of high-resolution mobile radar data in tornado intensity determination. Wea. Forecasting, 29, 799-827, https://doi.org/ 10.1175/WAF-D-14-00026.1.

Tanamachi, R. L., H. B. Bluestein, W. C. Lee, M. Bell, and A. L. Pazmany, 2007: Ground-based velocity track display (GBVTD) analysis of W-band radar data in a tornado near Stockton, Kansas, on 15 May 1999. Mon. Wea. Rev., 135, 783-800, https:// doi.org/10.1175/MWR3325.1.

,-- J. B. Houser, S. J. Frasier, and K. M. Hardwick, 2012: Mobile X-band, polarimetric Doppler radar observations of the 4 May 2007 Greensburg, Kansas, tornadic supercell. Mon. Wea. Rev., 140, 2103-2125, https://doi.org/10.1175/MWR-D11-00142.1.

,-- M. Xue, W. C. Lee, K. Orzel, S. Frasier, and R. M. Wakimoto, 2013: Near-surface vortex structure in a tornado 
and in a sub-tornado-strength convective-storm vortex observed by a mobile, W-band radar during VORTEX2. Mon. Wea. Rev., 141, 3661-3690, https://doi.org/10.1175/MWR-D12-00331.1.

Wakimoto, R. M., and Coauthors, 2016: Aerial damage survey of the 2013 El Reno tornado combined with mobile radar data. Mon. Wea. Rev., 144, 1749-1776, https://doi.org/10.1175/MWRD-15-0367.1.

Weiss, C. C., T. Cermak, R. Metzger, A. Reinhart, and P. Skinner, 2014: Insights into tornado structure afforded by highfrequency mobile radar. 27th Conf. on Severe Local Storms, Madison, WI, Amer. Meteor. Soc., P9.4, https://ams.confex.com/ ams/27SLS/webprogram/Paper255350.html.

Wurman, J., 2002: The multiple-vortex structure of a tornado. Wea. Forecasting, 17, 473-505, https://doi.org/10.1175/15200434(2002)017<0473:TMVSOA>2.0.CO;2.

_, and S. Gill, 2000: Fine-scale radar observations of the Dimmitt, Texas (2 June 1995), tornado. Mon. Wea. Rev., 128, 2135 2164, https://doi.org/10.1175/1520-0493(2000)128<2135: FROOTD $>2.0 . \mathrm{CO} ; 2$.
- , and M. Randall, 2001: An inexpensive, mobile, rapid-scan radar. Preprints, 30th Int. Conf. on Radar Meteorology, Munich, Germany, Amer. Meteor. Soc., P3.4, https://ams.confex.com/ ams/30radar/techprogram/paper_21577.htm.

— , and K. Kosiba, 2013: Finescale radar observations of tornadoes and mesocyclone structures. Wea. Forecasting, 28, 11571174, https://doi.org/10.1175/WAF-D-12-00127.1.

_ J. Straka, and E. Rasmussen, 1996: Fine-scale Doppler radar observations of tornadoes. Science, 272, 1774-1777, https://doi.org/ 10.1126/science.272.5269.1774.

—, Y. Richardson, C. Alexander, S. Weygandt, and P. F. Zhang, 2007: Dual-Doppler and single-Doppler analysis of a tornadic storm undergoing mergers and repeated tornadogenesis. Mon. Wea. Rev., 135, 736-758, https://doi.org/ 10.1175/MWR3276.1.

_, K. Kosiba, and P. Robinson, 2013: In situ, Doppler radar, and video observations of the interior structure of a tornado and the wind-damage relationship. Bull. Amer. Meteor. Soc., 94, 835-846, https://doi.org/10.1175/ BAMS-D-12-00114.1. 